\title{
BOSQUES DE TAMARUGOS, UN ACERCAMIENTO ETNOHISTÓRICO PARA EL ESTUDIO DEL PALEOCLIMA EN EL DESIERTO DE ATACAMA
}

\author{
FOREST OF TAMARUGOS, AN ETHNOHISTORC APPROACH \\ FOR THE STUDY OF PALEOCLIMATE IN THE ATACAMA DESERT
}

\author{
Mario A. Rivera Díaz*
}

\begin{abstract}
Este trabajo propone complementar el proyecto dendroarqueológico que llevamos adelante en la Pampa del Tamarugal con información de mapas, descripciones y observaciones de cronistas, viajeros, misiones científicas y registros eclesiásticos acerca de la dinámica de paisaje del desierto de Atacama en tiempos históricos, en particular la presencia de formaciones boscosas a partir del siglo XVI y la disponibilidad de agua. Mediante estrategias etnohistóricas intentamos averiguar ¿qué pudo haber causado pérdida importante de grandes extensiones de bosques de Prosopis en sectores del desierto de Atacama? ¿Hubo cambios significativos del medio ambiente que pudieron haber condicionado el paisaje del desierto? ¿Cuál pudo haber sido el impacto humano en el medio ambiente y viceversa?
\end{abstract}

Palabras claves: Dendroarqueología, tamarugos, etnohistoria, Pampa del Tamarugal, desierto de Atacama.

This paper complements the dendroarchaeology project by gathering data from maps, descriptions and observations from chroniclers, travelers, scientific missions, and church records, in historic times, in particular the existence of forests from XVI century on and the availability of water. By using ethnohistoric strategies about the dynamics of the landscape we tackle questions such as, what could have caused the loss of such big forests of Prosopis in some areas of the Atacama Desert? Were there any significant environmental changes that could have conditioned the arid landscape? What could have been the human impact on the environment and viceversa?

Key words: Dendroarchaeology, tamarugos, ethnohistory, Pampa del Tamarugal, desierto de Atacama.

\section{Introducción}

Vernon Scarborough ha enfatizado la importancia del estudio respecto del manejo del agua en términos globales, en especial porque el elemento agua es considerado como el recurso natural más preciado susceptible de ser manipulado y controlado (Scarborough 2003:1). El agua, desde el punto de vista humano, constituye la esencia de la vida misma.

El acceso al agua, como sus utilizaciones en la alimentación y protección o resguardo, consideradas estas necesidades básicas, ha sido asumido mediante reglas culturalmente prescritas. Es mediante un estudio como el que estamos dando cuenta parcialmente en este trabajo que podremos llegar a conocer mejor acerca de los orígenes sociales y las actividades de mantenimiento asociadas con el desarrollo complejo de los sistemas acuíferos y cómo estas sociedades han desarrollado aspectos fundamentales de su economía, su organización política y relaciones de poder en el transcurso del tiempo, condicionadas por un conjunto de factores, físicos, químicos, climáticos y culturales, que han afectado la disponibilidad del recurso agua y su subsiguiente uso.

Por otro lado, el estudio del manejo del agua también constituye una preocupación de la situación actual. Las condiciones áridas del ambiente en donde los recursos de agua, tanto natural como artificial, están bajo un estrés extremo. Su utilización indiscriminada que favorece una diversidad de actividades constituye una amenaza real a las condiciones de vida de los grupos humanos que por siglos han hecho del medio ambiente árido su hábitat.

Estudios previos realizados en diversas zonas del desierto de Atacama, y en especial en las áreas de Guatacondo y Tarapacá, demuestran que esta área ha sido dramáticamente más productiva en el pasado (Figura 1). De la misma forma, el hecho que las sociedades pretéritas se hayan podido desarrollar en estos ambientes y mantener niveles demográficos más altos que los actuales requieren de una explicación.

\footnotetext{
* Scientific Affiliate, Integrative Research Center, Field Museum of Natural History, Chicago, U.S.A. Correo electrónico: marivera41@gmail.com
} 


\section{REGIÓN DE TARAPACÁ - - ÁREA DE ESTUDIOS}

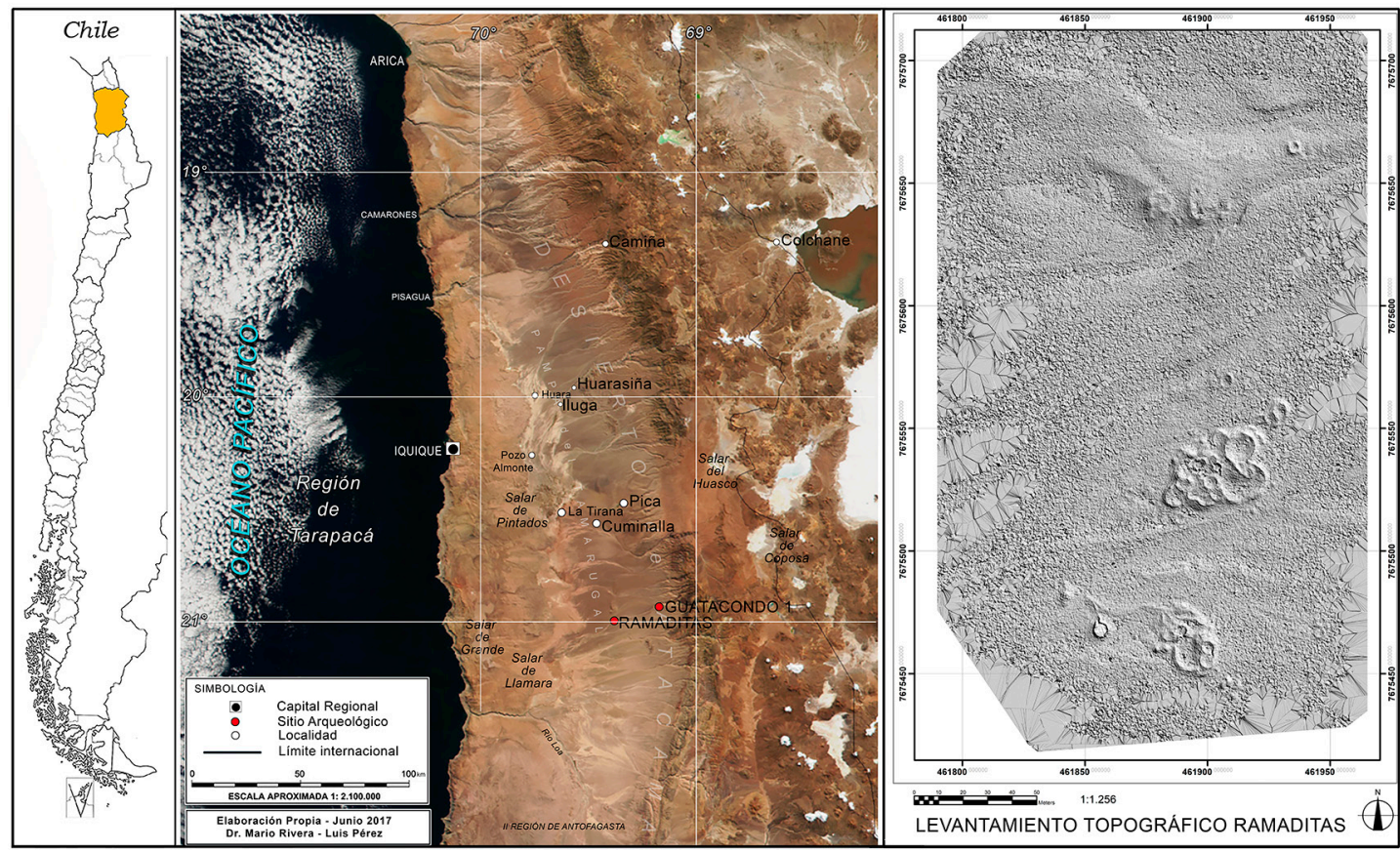

Figura 1. Mapa de la región Norte de Chile con detalle del sitio de Ramaditas en la Pampa del Tamarugal.

Por estas razones, seguimos interesados en conocer el rol del agua en relación con el modo selectivo de utilizar recursos de plantas silvestres y domesticadas asociadas a prácticas agrícolas. Igualmente continuamos investigando acerca de la disponibilidad de este recurso teniendo en cuenta las cambiantes condiciones medioambientales de estos sitios durante su ocupación. En este contexto, el tamarugo ha desarrollado un papel fundamental en el estudio de los primeros establecimientos humanos en el área y más adelante explicaremos acerca de nuestro interés en estudiarlo.

Este planteamiento general es el que nos motivó a estudiar el caso de las condiciones extremadamente áridas del desierto de Atacama y en particular de los habitantes del sitio aldea de Ramaditas. Aunque sabemos muy poco del proceso de sedentarización en esta parte de los Andes, es indudable que ha habido un proceso previo al desarrollo incaico en el área con etapas que han hecho posibles diferentes formas o modos de vida. De allí que nos interese el proceso de formación aldeana en el ámbito tarapaqueño.

El desierto de Atacama es el desierto más árido del planeta, donde la precipitación media anual no rebasa los $12 \mathrm{~mm}$ (Clarke 2006). La antigüedad del desierto se retrotrae al menos al Triásico. Las condiciones actuales de hiperaridez datan del Mioceno debido al mismo fenómeno que actualmente afecta la región, es decir, como resultado de la confluencia entre la zona subtropical de alta presión, la helada corriente de Humboldt y los vientos marítimos que llegan al desierto (Clarke 2006).

A pesar de su extrema aridez, existen evidencias que durante el Pleistoceno, e intermitentemente en el Holoceno, la región ha experimentado cierto grado de variabilidad climática. Varios investigadores se han preocupado de estudiar este fenómeno en los últimos años (e.g., Grosjean et al. 1997; Latorre et al. 2006; Rech et al. 2002, 2003a, 2003b) dirigiendo su atención al cambio climático en la zona. Por ejemplo, Grosjean et al. (1997) demostraron que entre 6200 y 3100 años antes del presente (AP) se registraron períodos de intensas lluvias en la región de la quebrada de Puripica en la parte norte del desierto localizada al sur de Ramaditas. Nuestro trabajo en curso en el sitio-aldea de Ramaditas consiste en investigar la instancia cuando la sociedad andina logra concretar su complejidad en el tiempo en que las tempranas aldeas estaban creciendo y desarrollándose en centros urbanos permanentes 
con un liderazgo político cada vez más centralizado en épocas anteriores al 300 DC y por tanto antecediendo la expansión del estado Tiwanaku. $\mathrm{Al}$ estudiar sitios ubicados en áreas marginales a la cuenca Titicaca esperamos obtener información respecto de establecimientos, distribución espacial, tamaño de la población y manejo de recursos que, eventualmente, pudiera dirigirnos hacia una mejor interpretación de la organización sociopolítica de estas comunidades.

En este contexto, las aldeas ubicadas en el entorno de Guatacondo definen el desarrollo Alto Ramírez que caracteriza gran parte del período Intermedio Temprano.

Guatacondo (G-I) corresponde a un establecimiento ubicado en la quebrada de Guatacondo cerca de $15 \mathrm{~km}$ al interior de Ramaditas, y parcialmente estudiada por Grete Mostny (1970) y C. Meighan (1980). De los cinco sitios-aldeas ubicadas a lo largo de esta quebrada, todos corresponden al período Intermedio Temprano. G-I está conformada por 110 estructuras circulares, rodeando un patio central, ocupando un área de 120 por 95 metros. Evidencias de postes de tamarugos en las entradas de las estructuras sugieren que los techos fueron cónicos y cubiertos de totora. En torno a las estructuras existen extensos campos de cultivos con canales de irrigación, un patrón que se repite en Ramaditas (Figura 2).

\section{Descripción del área de Ramaditas}

El sitio-aldea de Ramaditas se encuentra ubicado a $125 \mathrm{~km}$ al SE de Iquique, y a 1.350 metros de altura en pleno desierto de Atacama, en la entrada de la quebrada de Guatacondo, en el sector que se pierde en la inmensidad del paisaje árido (Figura 1). El sitio arqueológico consiste en tres conjuntos arquitectónicos, un montículo relativamente grande, estructuras domésticas individuales ubicadas sin un orden preciso y un área considerable dedicada a campos de cultivos. El complejo completo representa una aldea con un patrón habitacional de tipo nucleado que cubre un área aproximada de tres hectáreas.

El conjunto número uno se ubica en el extremo sur del sitio, adyacente a la quebrada. Se caracteriza por dos estructuras circulares que se anexan a las murallas externas, una plaza o kancha circular amurallada, y dos compartimentos internos divididos por un muro interno (Figura 3). El conjunto número dos es más pequeño, con estructuras circulares concentradas en torno a un patio central cuyo diámetro máximo alcanza 15 metros. El conjunto número tres

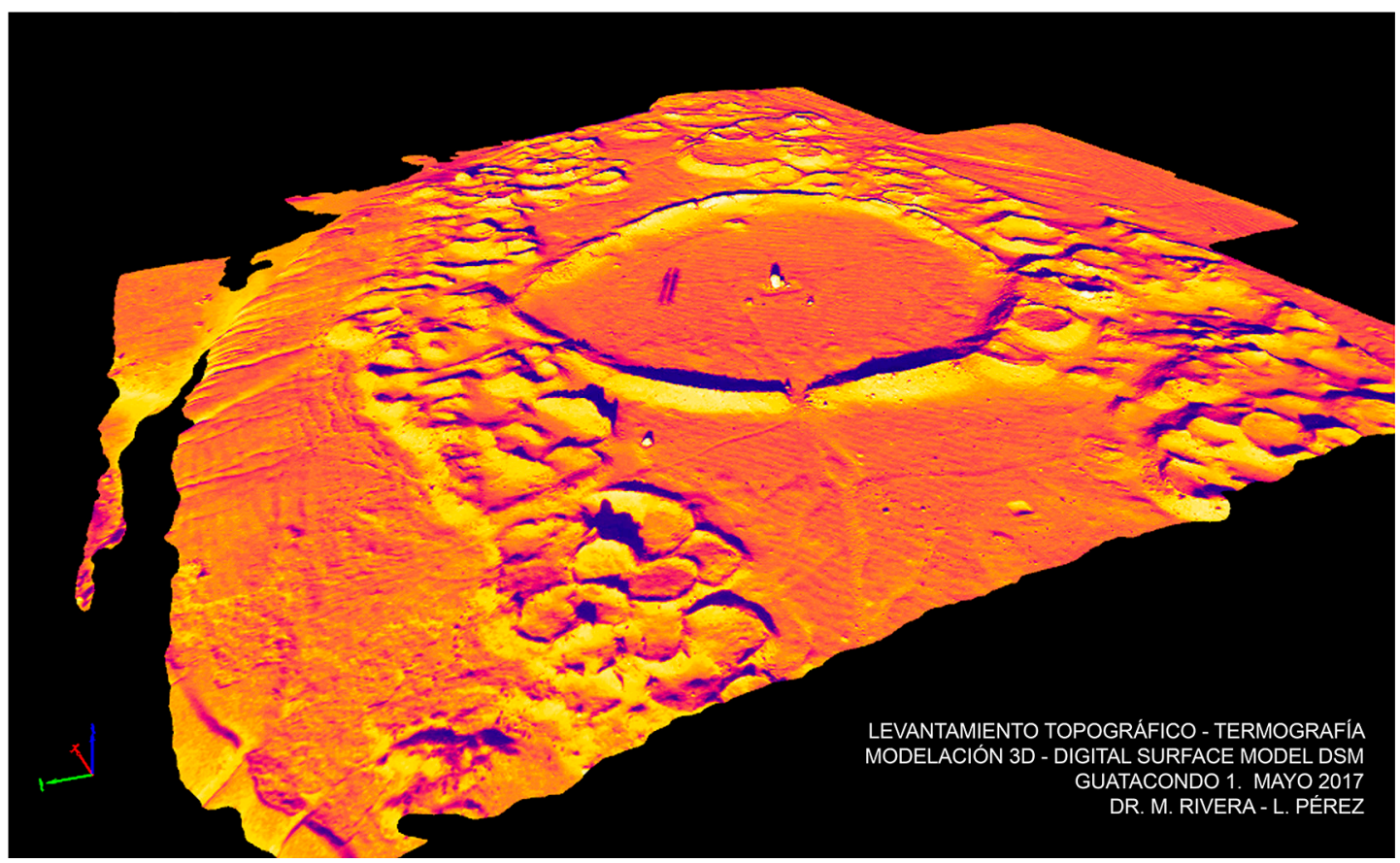

Figura 2. Conjunto aldeano de G-1, levantamiento topográfico termografía modelación 3-D. 
es el más grande y está ubicado al norte del sitio. Está compuesto por varias estructuras circulares y otras en forma de medio arco, aglutinadas con dimensiones aproximadas de 28 x 68 metros.

Rodeando estos conjuntos se encuentra una extensa área con campos de cultivos caracterizados por relictos de surcos simétricos, dispuestos en una red de canales principales y secundarios que conectan a bocatomas ubicadas en el cauce principal de la quebrada y regulada por empozamientos artificiales.

El área de Ramaditas/Guatacondo exhibe importantes remanentes de actividades agrícolas y evidencias de ocupación humana con restos arquitectónicos concentrados en dos aldeas principales, extensos campos de cultivos, y rasgos tales como reservorios de agua, pequeños estanques, pozos artesianos, una extensa red de canales y dispositivos para controlar el flujo del agua. El área es importante tanto desde el punto de vista climatológico como arqueológico debido a que se ubica gran cantidad de restos culturales que atestiguan una ocupación humana importante así como el uso de la tierra y prácticas agrícolas que estaban en pleno desarrollo hace 2500 años. Procesos postdeposicionales y tafonómicos han contribuido a la conservación excepcional de materiales que incluye restos macro

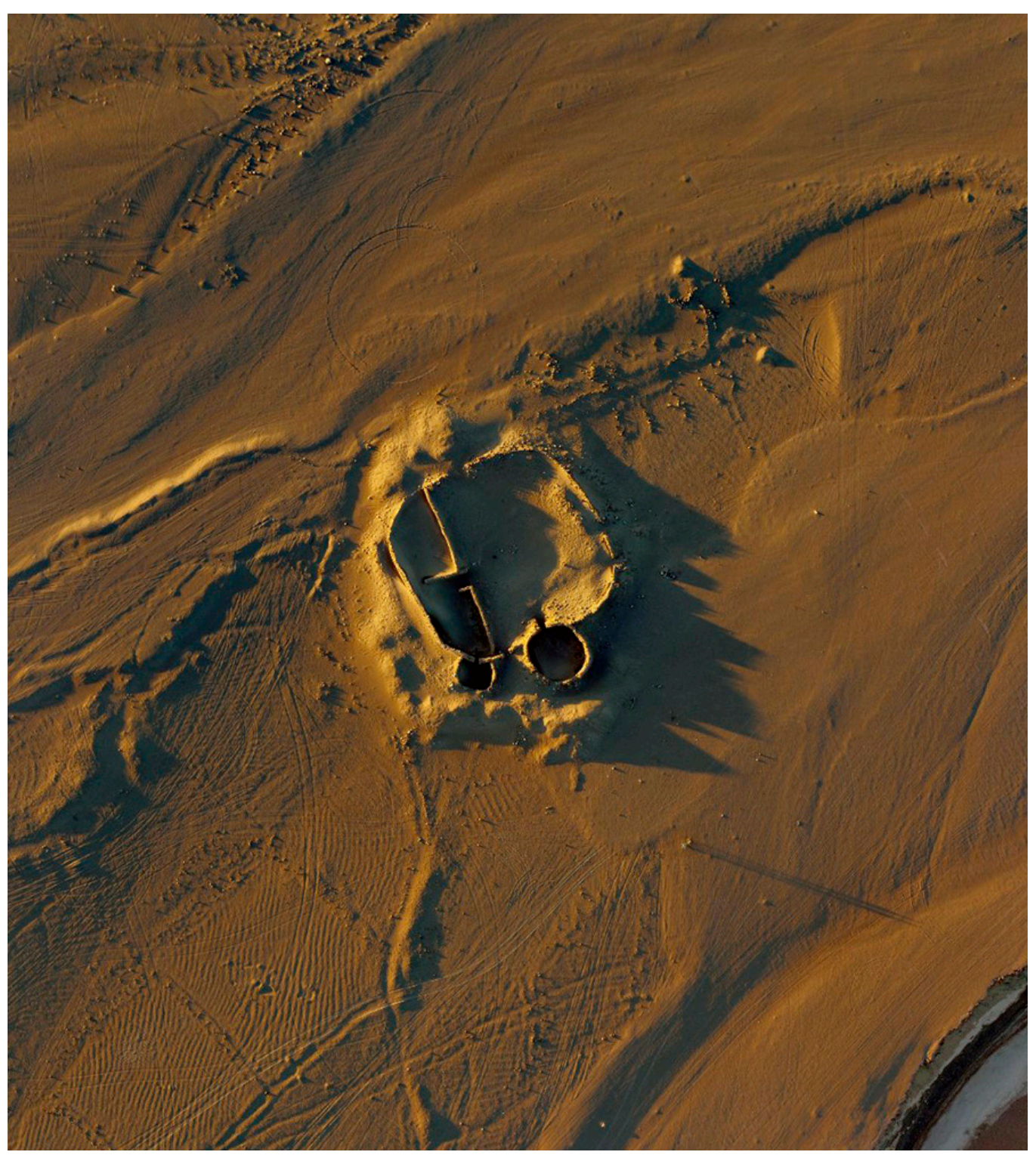

Figura 3. Vista aérea del complejo 1 de Ramaditas. 
y microbotánicos, así como cutículas de plantas y palinomorfos contenidos en sedimentos y fecas humanas susceptibles de análisis.

A partir de nuestro estudio en Ramaditas, el principal objetivo es integrar información de diversos sitios de las áreas mencionadas con el fin de obtener un cuadro más comprehensivo de las condiciones paleoclimáticas que han afectado el establecimiento de poblaciones humanas en el período comprendido entre 800 y 100 A.C. Corresponde este período a la etapa del desarrollo cultural andino cuando, a raíz de un proceso de sedentariedad inicial, comienzan a mostrar signos inequívocos de complejidad social caracterizado por una cierta estabilidad económica que en casos como Ramaditas llega a producir un excedente agrícola, diferenciación social, existencia de grupos de especialistas y una elite capaz de insertar estos grupos en un marco de interacción regional.

Nuestra hipótesis se enmarca en el interés por conocer si las condiciones ambientales que permitieron establecimientos humanos cada vez más permanentes en los ambientes hoy de extrema aridez que caracterizan los cultivos más tempranos de Ramaditas/Guatacondo realmente afectaron su desarrollo. En especial, corroborar si efectivamente las condiciones del entorno desértico fueron más húmedas que las actuales, y que a partir de 500 años antes de la Era se producen condiciones de aridez y recalentamiento paulatino que pudieron haber condicionado la permanencia de estos grupos. $\mathrm{Si}$ esto fuera efectivo, entonces las condiciones ambientales desarrolladas entre 500 y 100 años antes de la Era pueden haber tenido un rango espacial mayor, pues estarían coincidiendo con registros paleoclimáticos que también involucran la cuenca del Titicaca.

\section{Las investigaciones dendrocronológicas}

Debido a que los registros paleoambientales del Hemisferio Sur entregan información atinente a cambio climático a nivel global, estamos llevando adelante investigaciones dendroarqueológicas basadas en análisis de anillas de crecimiento de Prosopis tamarugo sp. que son indicativas de las condiciones climáticas en el tiempo, aprovechando el hecho que en el sitio de Ramaditas recuperamos algunos postes de sustentación de los techos de las habitaciones.

Dentro de los registros paleoambientales, la dendrocronología constituye uno de los registros más importantes y exactos, al tener una resolución anual e involucrar escalas temporales que son aptas para el estudio de los cambios ambientales presentes y pasados. El uso de vigas de madera del género Prosopis en la construcción de las viviendas, más la disponibilidad de árboles vivos en el área (Prosopis tamarugo Phil. y Prosopis alba Griseb.), como a la vez de material enterrado producto de las inundaciones a causa de las precipitaciones en la meseta altoandina, ha permitido colectar material suficiente para dar los primeros pasos en la realización de las primeras cronologías que permitirán hacer reconstrucciones del clima del pasado en el desierto de Atacama. Para ello hemos utilizado material tanto arqueológico como vivo, cuyos análisis permitirán comprender la dinámica del ciclo hídrico y del manejo del desierto por parte de un puñado de hombres y mujeres que lograron hacer producir una de las áreas más inhóspitas del planeta hace más de 2600 años. Situación que permitirá la comprensión y mejor utilización de los recursos presentes como futuros (Rivera et al. 2010, Rivera y Dodd 2013, Dodd y Rivera 2012).

Fisionómicamente la Pampa del Tamarugal es una gran cuenca endorreica que en la actualidad se encuentra completamente seca y cubierta en las partes más bajas con una gruesa capa de sales. Esta cuenca se encuentra rodeada en la parte oriental por grandes abanicos aluviales formados a la salida de las quebradas que abandonan la cordillera de los Andes formando depósitos pedemontanos. En la parte occidental, la pampa se ve limitada por la cordillera de la Costa. Se extiende desde $19^{\circ} 17^{\prime} \mathrm{S}$ hasta los $21^{\circ} 20^{\prime} \mathrm{S}$ de latitud Sur. En estas condiciones es que se desarrolla el tamarugo (Prosopis tamarugo Phil.), árbol que pertenece al orden Leguminosas, familia de las Mimosáceas. Es una especie endémica de un área específica del desierto de Atacama que a pesar de su gran importancia ecológica es poco conocida, ignorándose las etapas de desarrollo desde su aparición, a pesar que tempranamente en el siglo XVIII fue objeto de estudio por Ruiz y Pavón de la Expedición de Alejandro Malaspina (2001 [1799]) (Figura 4).

Estudios previos han determinado edades aproximadas a los cuatrocientos años de edad, creciendo sobre los salares de la Pampa del Tamarugal con ausencia casi total de precipitaciones, aprovechando solamente las aguas subterráneas.

Como la dendrocronología contribuye información en tres categorías para el análisis e 
interpretación de la historia de la Humanidad: cronología, comportamiento y medio ambiente (Dean y Doyel 2006), los análisis que se obtienen deben ser contrastados por sus variaciones mediante largos periodos, en donde los registros etnohistóricos y paleoambientales de los bosques de tamarugos en la Pampa del Tamarugal son claves en la relación hombre-ambiente. Comprender la disponibilidad del recurso hídrico fue crucial en estas circunstancias y, en directa relación, la situación ambiental. En un panorama más amplio, cuestiones de espectro fundamental se constituyeron en nuestros objetivos mayores, a saber, ¿qué pudo haber causado la desaparición de las formaciones boscosas de Prosopis en Atacama? Si existió un cambio importante de las condiciones ambientales de la Pampa del Tamarugal y por extensión al desierto de Atacama, ¿cuál pudo haber sido la causa de estos cambios?, y ¿cuál fue el impacto humano sobre el medio ambiente o viceversa? (Figuras 5 y 6 ).

A raíz de las prospecciones realizadas en los últimos años entre los $21^{\circ} \mathrm{S}$ y $21^{\circ} 30^{\prime} \mathrm{S}$, y antecedentes aportados por Raquel Pinto hemos podido mapear áreas extensas de formaciones boscosas que aparecen hoy como relictos. El área más importante está ubicada en el sector de Llamara, donde se encuentra un segmento de bosque prístino compuesto aproximadamente de 40\% del bosque original (Pinto 2009). Aún más, análisis experimentales de anillas fue realizado con muestras de tamarugos modernas y arqueológicas que han entregado las primeras secuencias para Atacama (Rivera et al. 2010). La Tabla 1 entrega información crítica acerca de la disponibilidad de agua y su utilización en el paisaje de Ramaditas en la época en que el área de Guatacondo fue ocupada por los primeros agricultores, caracterizando el desarrollo de aspectos fundamentales de la economía prehispánica, su organización política y las consecuentes relaciones de poder. Los cambios episódicos de la disponibilidad de agua durante el Holoceno Medio y posterior en la Pampa del Tamarugal pueden relacionarse a cambios de mayor escala en relación con las fuentes de humedad del

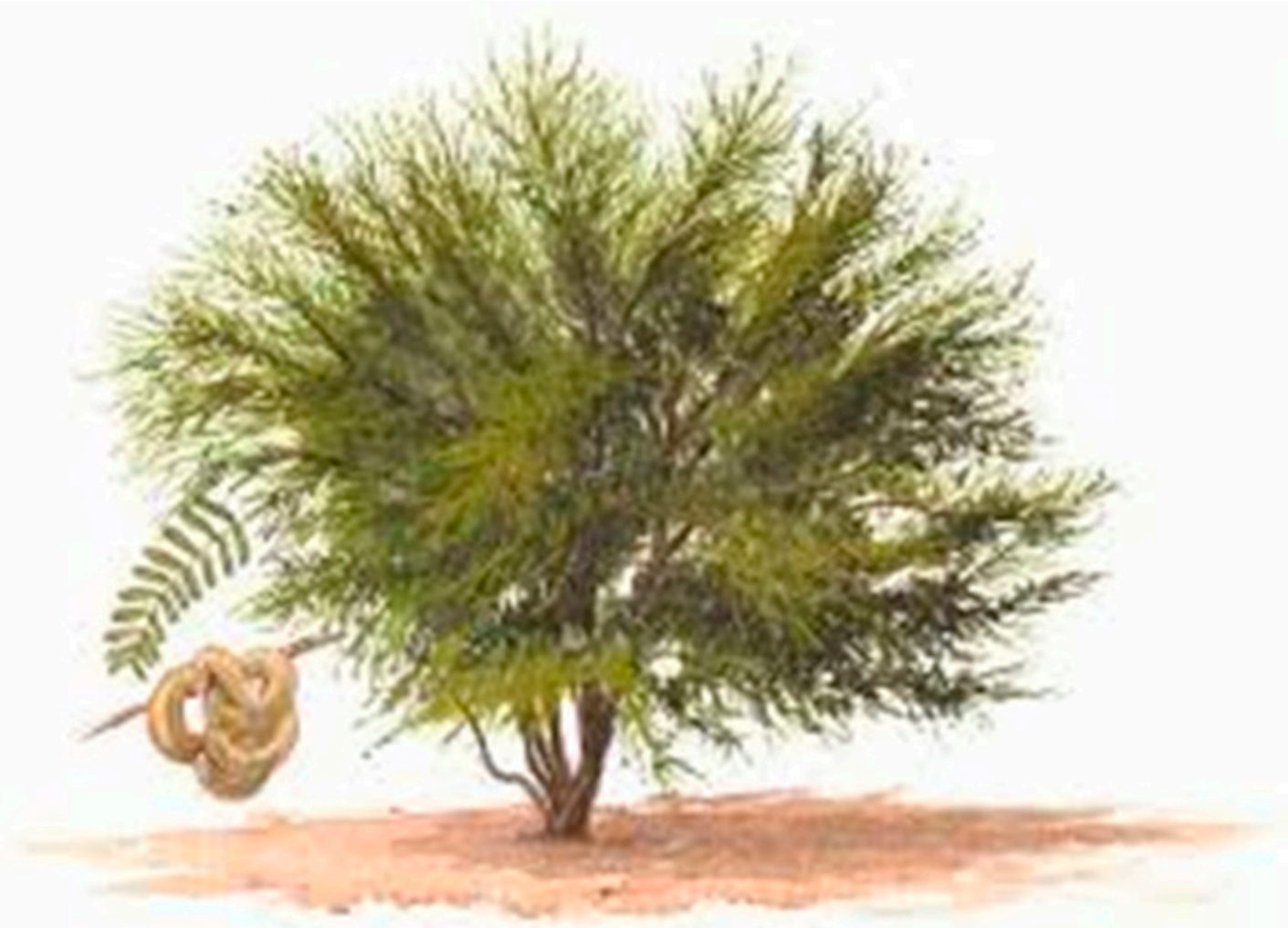

Figura 4. Ejemplar de tamarugo (Prosopis tamarugo sp.), según Ruiz y Pavón, Malaspina (2001) [1799]. 


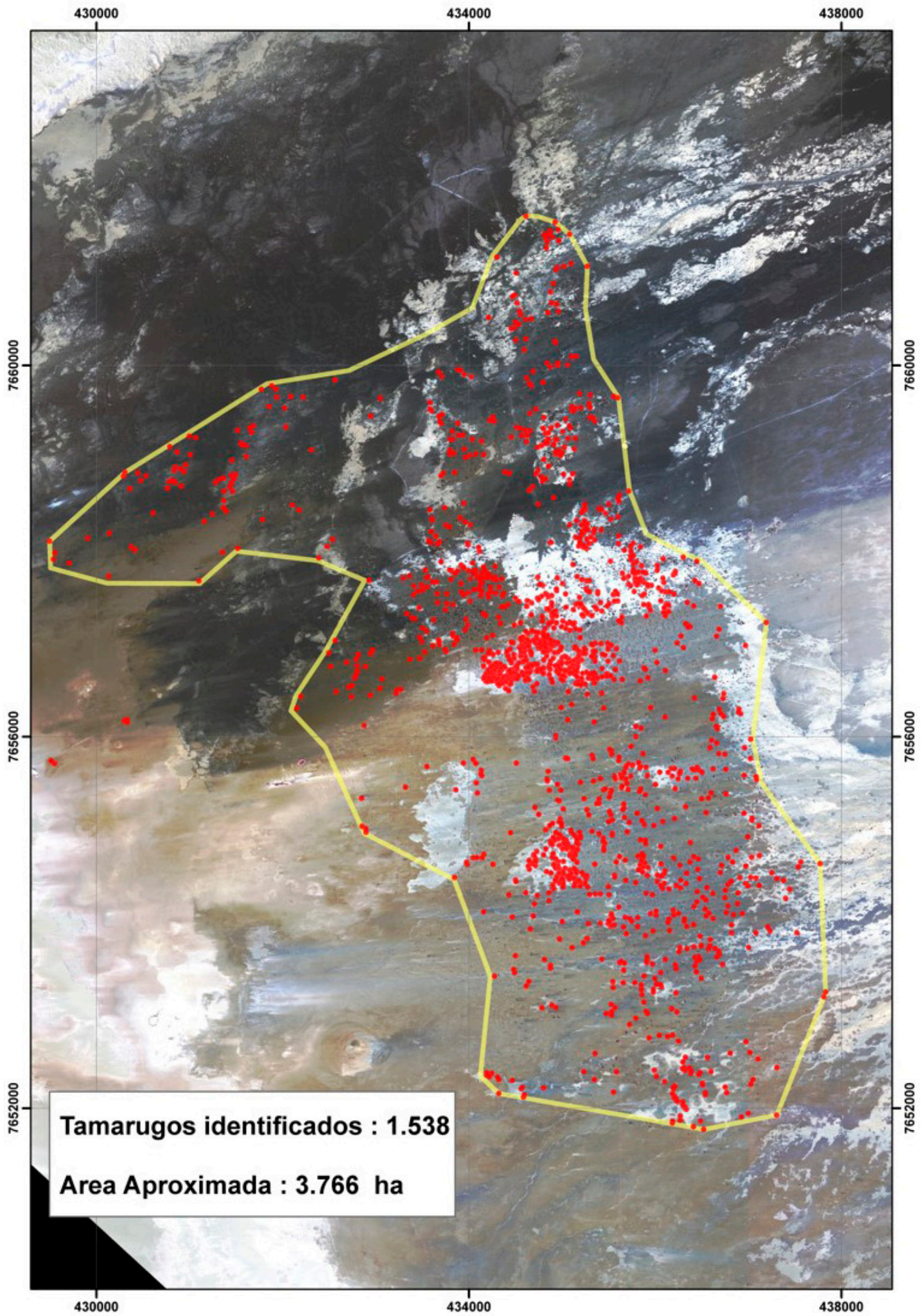

Figura 5. Distribución de relictos de tamarugos, bosque del área de Llamara y Monte Soledad (Pinto 2009). 


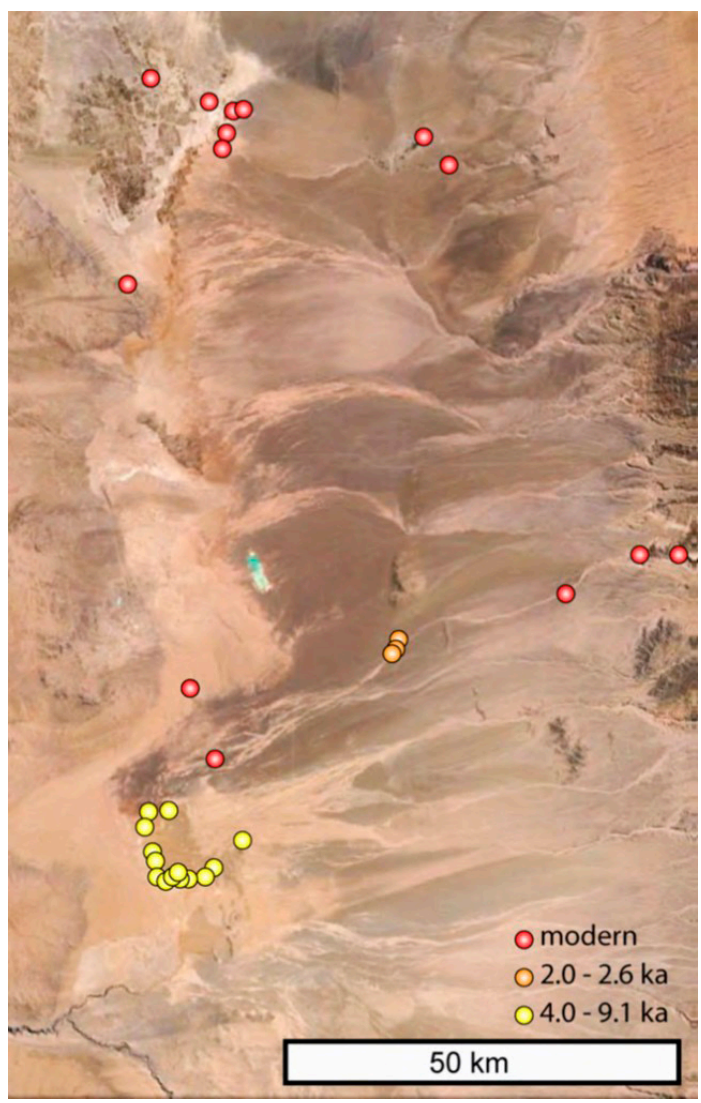

Figura 6. Composición de ejemplares de tamarugos del bosque Llamara y Monte Soledad, de acuerdo con proveniencia y antigüedad: modernos, arqueológicos (2000 a 2600 años) y relictos naturales (4000 a 9100 años).

Pacífico y Atlántico. Los estudios dendrológicos normalmente acceden a variadas fuentes de agua como por ejemplo precipitaciones estacionales, agua de superficie, fuentes de agua contenidas en suelos húmedos, y otros. En ausencia de estas fuentes, las formaciones de tamarugos que crecen en condiciones de aridez son muy sensibles a las sequías y cambios de condiciones climáticas. Durante el Holoceno
Tardío (2,4-1,8 kya) los valores $\delta^{18} \mathrm{O} \%$ promedio, indicados en la Tabla 1, disminuyen paulatinamente hasta los tiempos más recientes, indicando que los cambios se deben posiblemente a los eventos ENSO en respuesta a las situaciones generadas en la temperatura superficial del Pacifico (SST). Podemos agregar que las muestras correspondientes a Ramaditas pertenecen a sitios arqueológicos, de allí la posibilidad de modifición por acción humana, lo que no podemos descartar (Rivera y Dodd, 2013). Sin embargo, la intensificación de la ocupación humana y su expansión por la agricultura en la región es muy probable que sea la respuesta a la intensidad de los eventos ENSO que proveen los recursos hidrológicos durante este periodo (Olson et al. 2014). Los estudios dendroarqueológicos que continuamos realizando, especialmente por medio de isótopos en regiones áridas como el desierto de Atacama, son de gran potencial para identificar recurrencias de recarga de agua en situaciones tan estresantes.

Como una forma de complementar el estudio de las variabilidades climáticas y ambientales del desierto de Atacama que posibilitaron el desarrollo de los primeros establecimientos humanos estables, con provisión de agua, surge la posibilidad de reunir información de mapas, descripciones y observaciones de cronistas, viajeros, misiones científicas, registros eclesiásticos y civiles respecto de las dinámicas del paisaje atacameño en tiempos históricos, en especial la existencia de formaciones boscosas y disponibilidad de agua en el área a partir del siglo XVI.

\section{Los datos etnohistóricos}

Ya mencionábamos que con el desarrollo de las investigaciones surgió otro objetivo, el de obtener información acerca de posibles formaciones boscosas

Tabla 1. Resultados de análisis de sitios Cumiñalla (moderno) y Ramaditas (arqueológico).

Fechados radiocarbónicos son con dos sigma, calibrados al SHca113 (Adaptado de Olson et al. 2014).

\begin{tabular}{cccc}
\hline Muestra & ${ }^{14} \mathrm{C}$ AP & Promedio $\delta^{18} \mathrm{O}$ en $\%$ & Número de anillas registradas \\
\hline C1301 & Moderno & 31,9 & 52 \\
$\mathrm{C} 1302$ & Moderno & 32,6 & 58 \\
$\mathrm{C} 1303$ & Moderno & 31,6 & 33 \\
$\mathrm{C} 1305$ & Moderno & 30,5 & 33 \\
RAM1213 & $1809-1876$ & 38,1 & 68 \\
RAM1301 & $2539-2463$ & 35,5 & 77 \\
RAM1302 & $2410-2493$ & 38,0 & 84 \\
\hline
\end{tabular}


de tamarugos en el pasado que pudieran registrar datos adicionales para el estudio de las condiciones paleoambientales en la zona e información de recursos acuíferos. Nuestro pionero reconocimiento del Camino del Inca en esta área, proyecto del Instituto de Investigaciones Arqueológicas y Restauración Monumental de la Universidad de Chile en Antofagasta, en conjunto con John Hyslop en 1980 nos ha motivado a revisar esta documentación en pos de lograr más datos pertinentes a la conformación de estas formaciones boscosas y la ubicación de aguadas que han servido el doble objetivo de recurso para el propio Qhapaq Ňan como recurso acuífero en conexión con las condiciones ambientales del pasado.

Una perspectiva etnohistórica acerca de la utilización del agua en el desierto de Atacama, especialmente referida a la Pampa del Tamarugal muestra que esta ha sido desde tiempos de la conquista europea descrita como el Despoblado de Atacama, aludiendo a lo vacío del territorio desde el punto de vista poblacional y de extrema aridez desde el punto de vista ambiental. Cristóbal de Molina, capellán de la expedición de Diego de Almagro, así lo menciona: en el despoblado de Atacama... que es un arenal de cien leguas, donde hay muy poco agua y yerba ni cosa verde; en todo el despoblado no se halla / agual, sino en cuatro o cinco partes (1934:24).

Efraín Trelles (1982:256) menciona la intensa actividad de hacer carbón de que se hace referencia en la encomienda a Lucas Martínez de Vegaso como pago a indios por servicios en las minas de Tarapacá. Evidentemente este servicio de hacer carbón debe haberse hecho a partir de madera de tamarugo, consecuentemente, la presencia de bosques debe haber sido un hecho manifiesto y disponible al tiempo de la conquista.

Sin embargo, también en estas descripciones se hace mención a la existencia de "puquios" o fuentes naturales de agua y que están siendo utilizadas como postas a lo largo del Camino del Inca. Notable es el sitio mismo de Puquios ubicado al sur de Tilomonte, en el extremo meridional del Qhapaq Nan (Niemeyer y Rivera 1983:94, Hyslop y Rivera 1984).

De la misma forma cronistas como Garcilaso de la Vega (1962) y Jerónimo de Bibar (1966) mencionan la existencia de "puquios" que fueron mantenidos de manera exclusiva por el Inka. Así lo refrenda Horacio Zapater en su publicación Los Aborígenes Chilenos a Través de Cronistas $y$ Viajeros, cita a Bibar, quien recorre el Norte a mediados del siglo XVI. Observó la importancia que algarrobales y chañarales tenían en su régimen alimenticio. Señala que molían la algarroba y la cocían en agua para preparar una bebida o brebaje y lo califica de "gustosa"... Bibar describe el uso del algarrobo en la construcción de sus viviendas, diciendo: Las casas en que habitan los indios son de adobe y doblados con sus entresuelos hechos de gruesas vigas de algarrobo que es madera recia. Señala que tenían apartamentos pequeños y redondos de adobes a manera de hornos, que les servían de granero y donde guardaban el maíz, papa, frejoles, quinua, algarroba y chañar (Zapater 1973).

Notable es también la referencia de Pedro Lozano de Machuca (1581/1965) de los intentos del Inka por realizar obras hidráulicas de desviación de canales hacia la Pampa del Tamarugal con el fin de incrementar las posibilidades agrícolas del área y, posiblemente, motivados por la presencia de bosques en ese sector. Esta sugerencia es confirmada más tarde por Antonio O'Brien, Teniente de Gobernador de Tarapacá en 1768 con la comisión para estudiar la factibilidad de conducir aguas de ciertas lagunas altiplánicas (lagunas de Lirima) a la Pampa del Tamarugal. En su Descripción del Valle o Pampa de Isluga y del Tamarugal que acompaña su plano, se refiere al aprovechamiento de los Prosopis (Figura 7). Así describe los montes de tamarugo:
Hay en él gran cantidad de crecidos árboles que llaman tamarugo, algarrobo y molles, muchas y crecidas retamas con un espeso e intrincado monte bajo, que en parte lo hacen impenetrable, por esta parte cerca del pueblo de Pica y es bastante húmedo y muy abundante en agua subterránea (Couyoumdjiam y Larraín 1975).

En el plano que logra levantar son evidentes las formaciones boscosas de tamarugos ${ }^{1}$, las que indudablemente incitaron a O'Brien a concebir la desviación de las aguas hacia esta planicie de la Pampa del Tamarugal. Pero el empuje inicial está dado por el Inka, de manera que los bosques existirían con bastante anterioridad (O'Brien 1765).

Los bosques de tamarugos han jugado un papel fundamental en la vida de los pueblos tarapaqueños. 


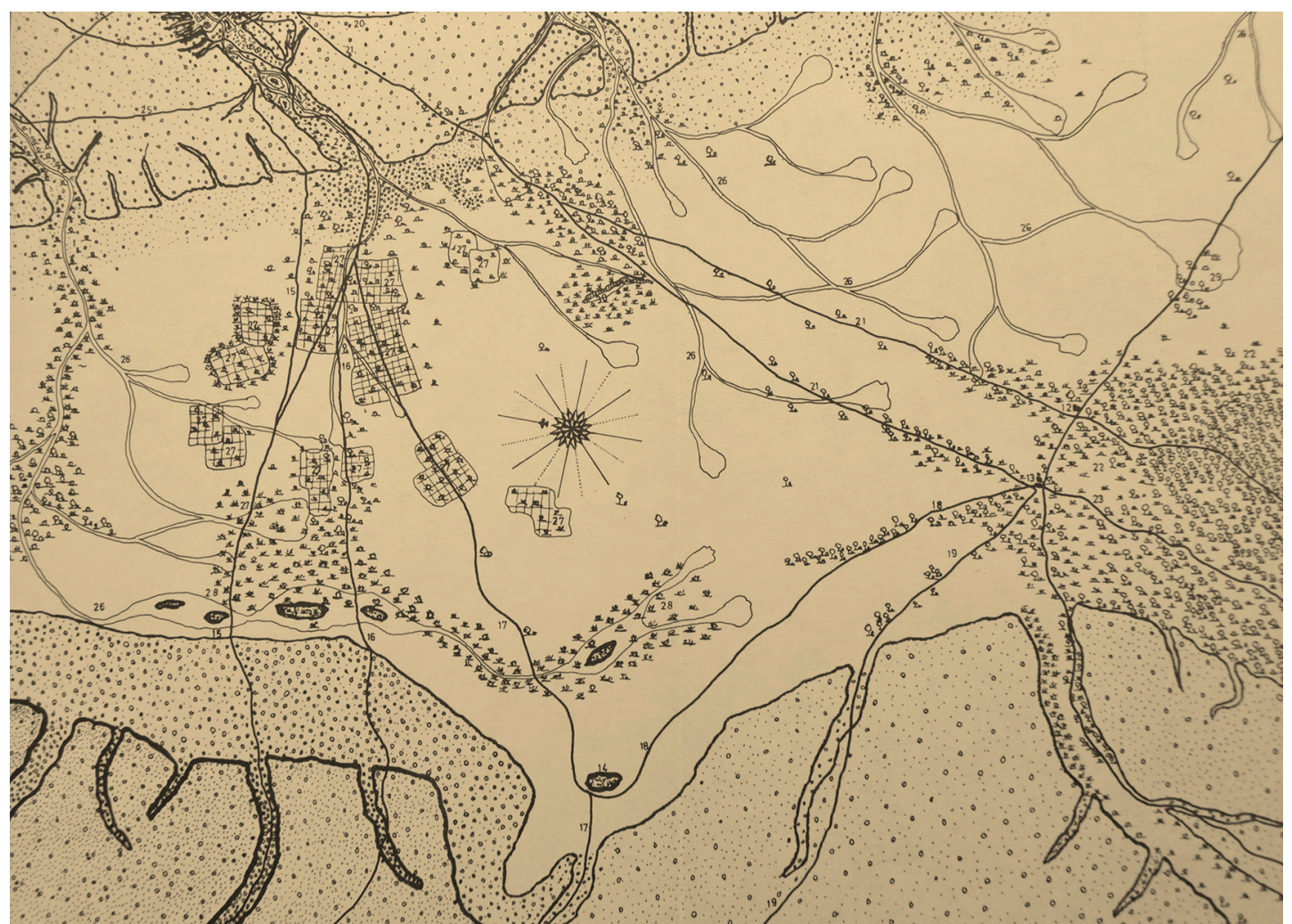

Figura 7. Sector de Pampa Iluga del mapa de O’Brien que muestra área con bosques de tamarugos (O’Brien 1765).

Tanto en el sitio aldea de Caserones en el sector inferior de la quebrada de Tarapacá y muy cerca de la Pampa del Tamarugal como en Ramaditas y G-1 en plena Pampa del Tamarugal donde se pierde la quebrada de Guatacondo, los establecimientos aldeanos utilizaron profusamente postes de tamarugo para la construcción de sus viviendas, de manera que la presencia de estos bosques era notable hace alrededor de 2500 años.

En el sitio arqueológico de Tarapacá 2-A, Delbert L. True y Harvey Crew ubicaron semillas y vainas de tamarugo y algarrobo en contextos arqueológicos de 5000 años de antigüedad, que representan actividades de cazadores de guanacos. De acuerdo con los autores, esto sugiere condiciones ambientales más húmedas (True y Crew 1980:74-76).

Análisis de muestras provenientes de Guatacondo revelan que la población consumió semillas de Prosopis con bastante frecuencia, llegando a constituirse en la fuente más importante de alimentación entre las plantas silvestres, junto con componentes del complejo de granos donde el maíz es fundamental (Tartaglia 1980:127-133). De nuestras propias excavaciones hemos recuperado piedras de moler desde los niveles más tempranos de la estructura 1 del complejo 1 de Ramaditas. Estas contienen abundantes residuos de frutos de tamarugos machacados, lo que constituye un factor importante acerca del consumo de estas vainas por parte de las poblaciones pretéritas que habitaron la Pampa del Tamarugal. Similar evidencias han sido recuperadas de la aldea G-1 (Rivera 2002:122-123, Cummings et al. 2005:202).

Grete Mostny en su informe de 1980 también hace referencia a la presencia de extensos bosques relictuales en la quebrada de Guatacondo junto al mismo emplazamiento donde se ubican los campos de cultivos, relacionando estos con condiciones hidrológicas especiales, que se repetirían en quebrada Maní (Mostny 1980:92).

En tiempos de la ocupación europea, el padre Alonso de Balsana se refiere así a esta situación,

El modo de vivir de estas naciones es el ser labradores, sus ordinarias comidas son maíz, lo cual siembran en mucha abundancia; 
también se sustentan de grandísima suma de algarroba, la cual recogen por los campos todos los años al tiempo que maduran y hacen de ella grandes depósitos; y cuando no llueve para coger maíz (o) el río no sale de madre para regar la tierra, pasan sus necesidades con esta algarroba, la cual no le es solo comida, mas también hacen de ella bebida, tan fuerte que nunca hay más muerte y guerras entre ellos que mientras dura el tiempo de la algarroba. En estos mismos tiempos della ha procurado nuestra compañía irse con ellos cuando le van a coger (y) ha catequizado y bautizado en aquel mesmo tiempo muchos infieles en el mismo monte de algarroba y confesado y predicado y hecho nuestros ministros (Balsana 1594).

En 1808, Francisco Javier de Mendizábal en su informe al virrey del Perú, a propósito de los planes de O'Brien, destacaba lo importante que era proteger el Monte del Tamarugal: formado en la dicha Pampa de Yluga por elevados y gruesos Arboles llamados Tamarugos, el qual se ba destruyendo y alejando con el continuo corte que se hace para leña y carbón (Mendizábal, 1808 en Hidalgo, 1985).

El Ministerio de Agricultura, por intermedio de la Corporación Nacional Forestal ha destacado que en pleno desierto de Atacama se encuentra la plantación endémica más extensa de país, hecho que hace replantear la historia forestal de Chile. Nos referimos al bosque de la Reserva Nacional Pampa del Tamarugal que con sus bosques de tamarugos y algarrobos plantados con fines ganaderos entre las décadas de los 40 y 60, es considerado el patrimonio forestal más grande del norte de Chile, con dos millones de especies (CONAF 2015:260).

Siguiendo el imperativo de CONAF, apuntamos que para hacer frente al uso intensivo del bosque con fines de obtener leña y carbón durante el auge salitrero de la zona, y para fomentar el uso ancestral y cultural del Prosopis como fuente de vida para las comunidades insertas en este territorio -la mayoría de origen aymara-, se han realizado diversas acciones que han permitido recuperar y reverdecer el gran pulmón verde de Tarapacá.

Hoy gran parte de la Pampa del Tamarugal se encuentra declarada área silvestre protegida con una superficie de más de 134 mil hectáreas, de estas, 22 mil son plantaciones de tamarugos. Incluso se encuentra en trámite en el poder legislativo chileno el proyecto de declarar el tamarugo como monumento nacional (Boletín Cámara Diputados 9903-12, Periodo Legislativo 2014-2018, Legislatura 362, Sesión N${ }^{\circ} 124$ Fecha 04-3 2015).

Otros antecedentes respecto de la existencia de bosques de tamarugos en pleno desierto se encuentran en Guillermo Billinghurst, quien describe en sus estudios pertinentes a recursos económicos de la Pampa a fines del siglo pasado:

... Existen bosques enteros sepultados por aluviones en las quebradas de Sipuca, Chipana, Maní, Tambíllo, Monte Soledad, etc., de la Pampa del Tamarugal...". "Desde $50 \mathrm{~cm}$ de hondura hasta 380 pies de profundidad, es posible hallar tamarugos inmensos sepultados por aluviones sucesivos..."

Respecto de esto, debemos mencionar los relatos hechos por "cazadores" de tamarugos y algarrobos para la producción de carbón-leña, que se hacía hasta mediados del presente siglo.

La existencia es tan grande que habría para una explotación de 50 años abasteciendo de carbón y leña a las provincias de Tarapacá y Antofagasta, y Bolivia misma sin interrupción..." "Las leñas de tamarugos y algarrobos, de Pintados al Norte, han sido consumidas desde tiempo inmemorial, y tienden a agotarse. Las regiones de Pintados y el Loa están inexploradas y su riqueza en leña fósil es incalculable, y solo se esperan las facilidades de comunicación, elementos de trabajo y el esfuerzo humano para mostrarse (Billinghurst 1886).

Y añade,

En época no remota la pampa del Tamarugal ostentaba una vegetación lozana, llena de vida -bosques de algarrobos, tamarugos y molles poblaban los puntos denominados Curaña, Iluga, Las Pillallas, La Tirana y La Soledad-. La inmensa cantidad de árboles en estado semifósil que se encuentran diseminados en toda la extensión de la pampa y cubiertos por densas capas de arena, los tamarugos que aun ofrecen sombra protectora a los viajeros, uno que 
otro molle secular que ha resistido a los rigores del clima profundamente perturbado por los cambios meteorológicos que ha debido experimentar esa región, así parecen demostrarlo (Billinghurst 1886:31).

\section{Luego indica}

el monte de tamarugos que es el que le ha dado nombre a toda la pampa, comenzaba, desde el puquio de Sánchez y el puquio de Guagama, y se extendía por frente de la quebrada de Pazos hasta cerca de la Piragua (Billinghurst 1886:39).

Respecto a la ubicación de los restos de tamarugos más antiguos que hemos podido ubicar, Billinghurst indica

La región austral de la pampa no tiene cultivos de ningún género. El monte de la Soledad, que se halla unos 15 kilómetros a1 Sur de Lagunas, y que se extiende en un trayecto de más de 13 kilómetros de Norte a Sur y como 6 kilómetros, de Este a Oeste, nada produce, en la actualidad, a excepción del fruto del tamarugo que mucho se asemeja al del algarrobo, pero que en aquel lugar está fuera del alcance de los que pueden utilizarlo. Ese monte no ha servido, hasta la fecha, sino para abastecer de leña a los habitantes de las huaneras de la costa, y de refugio a los que transitan por esa parte con dirección a Quillagua (Billinghurst 1886:58).

Por su parte, Antonio Raimondi, científico italiano arraigado en Perú y gran conocedor del territorio de su país, describe algunos de estos "montes" o bosques de tamarugos en la Pampa del Tamarugal. Estos datos están contenidos en su Libreta No.2 a propósito de su viaje a Tarapacá en 1852-3 y recientemente compilada por Luis Castro et al. (2017).

El día 12 salimos de Challapozo con dirección a la Aguada de Santa Ana. Después de dos leguas de un camino muy regular llegamos a un bosque de tamarugos llamado Monte Grande. Es muy delicioso el pasar a la sombra de estos árboles muy verdes después de tanta aridez, más una lástima muy grande es que entre poco tiempo también éstos casi desaparecerán por dar luego a un desierto; porque los van cortando para hacer leña y transportarla a las oficinas del salitre (Raimondi 1853:21).

Más adelante consigna,

Después continuamos el camino hacia La Noria pasando por muchos calichales, donde [fuimos] haciendo excavaciones para ver si había borato, encontramos en varios puntos un poco de éste en masa y una pequeña cantidad en bolas, más lo que extraña mucho es ver la cantidad de troncos de tamarugo que se encuentran enterrados, lo que hace suponer hayan sido estos lugares en otro tiempo un monte muy espeso (Raimondi 1853:21-22).

Finalmente, Raimondi confirma la existencia de gran tamarugal en los alrededores de La Tirana, bosque que CONAF ha logrado conservar como reserva natural:

Cerca de La Tirana existe un monte de tamarugos bastante grande habiéndose prohibido el corte bajo pena de una multa porque de otro modo no habría al presente existido un solo árbol cortándose para hacer leña y venderla a las oficinas del salitre. El camino que conduce de La Tirana a Tarapacá tiene 14 leguas de largo y es muy bueno. Casi toda la pampa indica por sus restos haber sido un monte de tamarugos, retamas y pillagas (Raimondi 1853:50).

Tanto Raimondi como Billinghurst refieren sus datos a lo sostenido por Bollaert y Smith en su mapa de la provincia de Tarapacá (Bollaert 1851, Smith y Bollaert 1860) (Figura 8).

El bosque que hemos logrado ubicar en las cercanías de Llamara, con antigüedad que supera los 9000 años probablemente era parte del mismo que se encontraba en los alrededores de Ramaditas y G-1 en la quebrada de Guatacondo, abarcando también parte de las estribaciones de quebrada de Maní. En la documentación que hemos podido revisar figura un gran bosque en la zona del Monte de la Soledad. Al respecto, Patricio Advis (2008), citando a Alejandro Bertrand (1879a y b), advierte: 


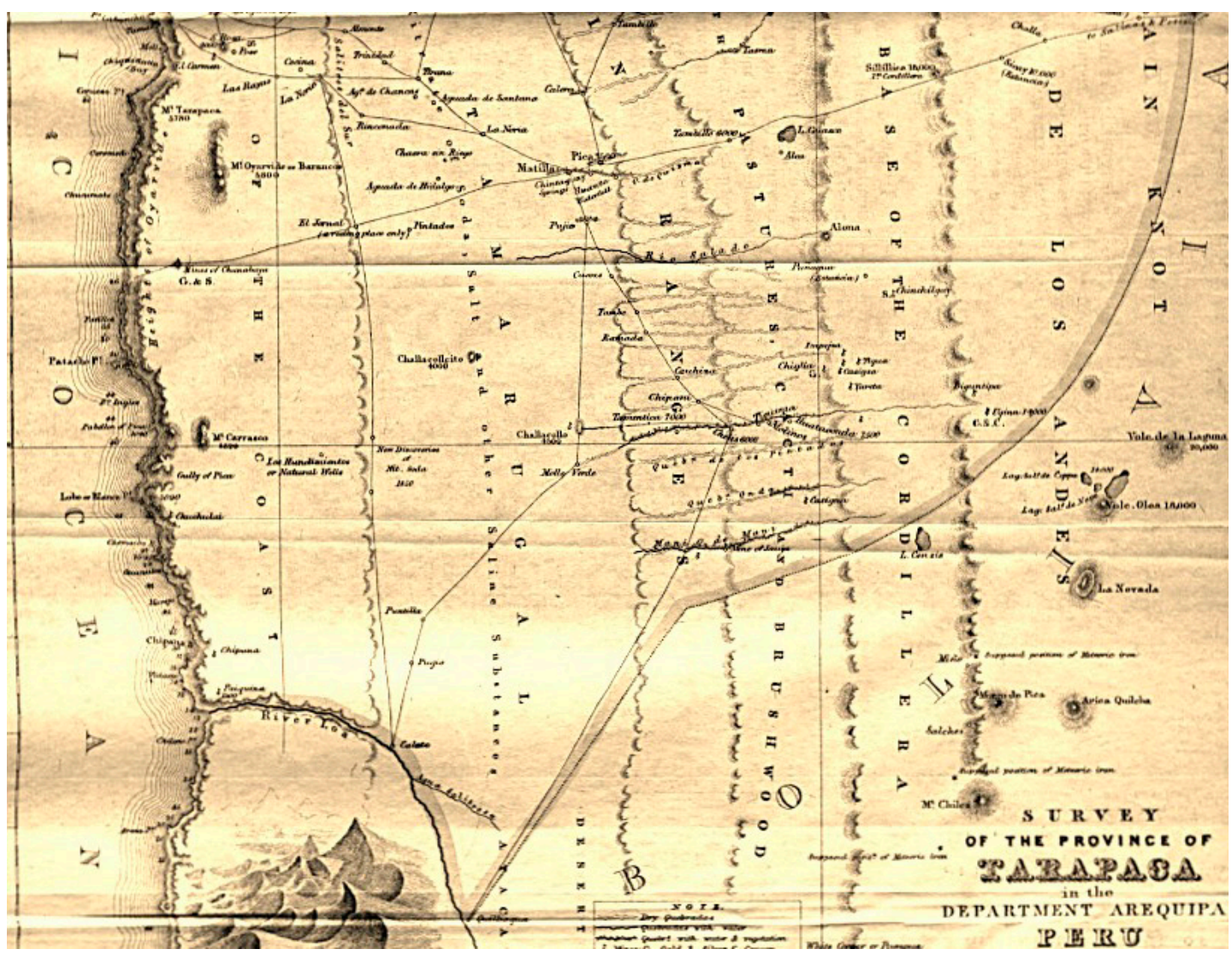

Figura 8. Sector Monte Soledad del mapa de Smith y Bollaert que muestra área de bosques de tamarugos (Smith y Bollaert 1860).

...el camino desde Quillagua a la cordillera presentaba una variante: esta soslayaba la quebrada de Maní orientándose directamente hacia la quebrada de Tamentica de la siguiente manera: de Quillagua avanzaba primero hacia el $\mathrm{N}$ unos $20 \mathrm{kms}$ hasta las aguadas del bosque de la Soledad, desde allí se desviaba hacia la cordillera surcando $35 \mathrm{~km}$ hasta el pequeño bosque y aguada de Molle Verde, desde este punto avanzaba los últimos $15 \mathrm{~km}$ en la misma dirección hasta las vertientes de Tamentica al pie de los Andes, en la desembocadura de la quebrada de Guatacondo (Advis 2008:152).

Luego nos advierte sobre la antigüedad de este sector y la importancia del mapa de Bertrand:

...la red caminera que presenta es anterior a la locomoción mecánica, es decir, corresponde a los caminos caravaneros de los tiempos prehispánicos, reutilizados durante la Colonia (Advis 2008:153).

En la Figura 9 reproducimos parte del mapa de Enrique Espinoza (1897) donde es posible identificar la ruta mencionada.

El historiador iquiqueño Mario Solezzi enfatiza el hecho que culminó con la destrucción del Monte de la Soledad durante la era del salitre. Al respecto comienza su artículo con la siguiente frase:

En la época salitrera se desarrolló un funesto proceso de deforestación que desoló la Pampa del Tamarugal. Ocupa un lugar destacado en ese sombrío capítulo de la historia de la antigua provincia de Tarapacá la irracional explotación del monte de la Soledad (Solezzi 1993:6).

Describiendo el paraje que componía el Monte de la Soledad, también conocido como Monte Verde, Solezzi agrega: 


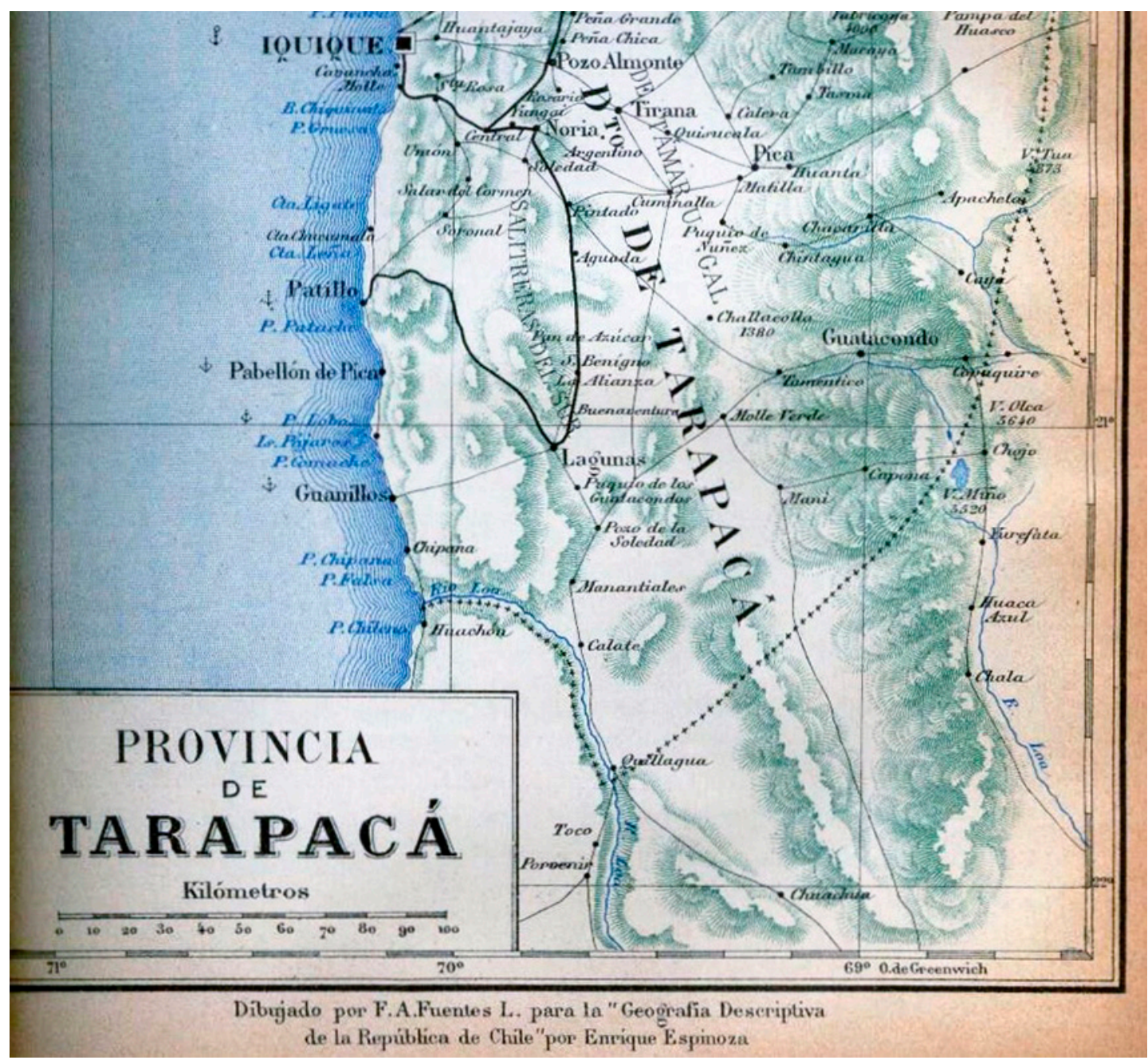

Figura 9. Sector Monte Soledad, Monte Verde, Challacollo que muestra bosques de tamarugos según mapa de F.A. Fuentes (Espinoza 1897).

El pueblo agrícola más cercano al monte de La Soledad era Huatacondo. Había un sendero desde la desembocadura de la Quebrada de Huatacondo que pasaba por ese bosque y seguía en dirección de Quillagua, a orillas del rio Loa. De esta manera sus habitantes llegaban a la Pampa del Tamarugal con el fin de explotar el monte. Estos también bajaban a Huanillos para extraer pequeñas cantidades de guano destinadas a abonar sus tierras agrícolas, utilizando otro sendero que atravesaba un área dotada de un puquillo llamado Huatacondos (Solezzi 1993:6).

El bosque fue explotado primero a partir de 1870 cuando se abrió la caleta de Huanillos a los intereses del guano. Continuó explotándose con la ocupación militar del ejército chileno a partir de la guerra del Pacífico, y culminó con la explotación del salitre. El Monte de la Soledad fue testigo, además, de un hecho insólito durante la guerra del 79. Solezzi relata esta circunstancia así:

En febrero y marzo de 1879 Chile ocupaba el litoral boliviano. En abril nuestro país declara la guerra al Perú y a Bolivia. Los peruanos preocupados de un posible avance chileno desde la "línea del Loa" hacia su territorio establecieron una pequeña columna en el monte de la Soledad para observar el movimiento de las tropas que ocupaban Quillagua, que pertenecía al Departamento de Tarapacá. Posteriormente, el Ejercito 
del Perú reforzó su presencia en ese lugar boscoso de la Pampa del Tamarugal. Eran poco más de 1.400 hombres al mando del coronel Mori Ortiz (Solezzi 1993:7).

Indudablemente, y aunque la depredación ya estaba en curso por varias décadas, los remanentes del bosque todavía eran considerables, pues fue utilizado efectivamente como refugio para esconder una tropa significativa en número. En el Boletín de la Guerra del Pacífico correspondiente a los años 1879-1881, se explica textualmente: "Existe otro camino que va a Quillagua tocando en los pozos de La Soledad a veinticinco leguas más o menos de Cumiñalla. En La Soledad hay abundancia de montes i de agua" (Boletín de la Guerra del Pacífico: 115).

Un aspecto más actual de La Soledad lo refiere Bowman al describir el trayecto hacia Quillagua:

As soon as we were able to manage it we started out again southward through the desert. Our first day's journey was from Lagunas seventy-five miles by trail southward by way of Monte la Soledad and the Pampa del Tamarugal to Quillagua, in the Loa valley. This course is now covered by a railway, but at that time it was virgin desert with no sign of habitation in that entire stretch except a cluster of huts at Monte la Soledad, where lived a family of three-father, mother, and son-maintaining themselves by means of a single well and a mixed flock of goats and sheep supplemented by a few riding mules and fowl. It was the smallest and the most isolated settlement that I have ever seen in the desert, but it was once a little larger, the rest of the inhabitants having gone to work in the nitrate fields (Bowman 1924:38, Figura 10).

La importancia de estos bosques de tamarugos era tal que las diferentes comunidades se disputaban los derechos a su usufructo. Así queda de manifiesto según lo indica Bente Bittmann siguiendo a Paz Soldán en relación a la lucha en pleno siglo XVII entre los naturales de Quillagua y de Pica por la posesión de los bosques de algarrobo y tamarugos, finalmente controlados por los de Pica (Paz Soldán 1878:57). Pero posteriormente, según expediente de
1742, sobre recursos de la zona de Quillagua, uno de los testigos declara haber visto a los indígenas de Pica y ChiuChiu recogiendo sus frutos del algarrobo en sus propios terrenos, esto es

... a la otra banda del río Loa en la cual están decididas las jurisdicciones, en una punta para abajo en que está el pueblo antiguo pertenece a esta jurisdicción y de ahí para arriba a la de Atacama, en una y otra parte ha habido siembra de algarrobos y los hay; los de arriba desde dicha punta han poseído y poseen los indios de Atacama, y los de abajo los indios de esta parcialidad sin permitir unos ni otros en sus cosechas que siempre los han ido a cojer sin que se propasen de sus linderos (Bittmann 1988:185, Paz Soldán 1878:55).

Entre los años 1850 a 1860 existían alrededor de 100 oficinas salitreras, la humareda de los fogones se perdía entre los innumerables cerros de la Noria. Los fogones eran alimentados con troncos de tamarugos y algarrobos de la Pampa del Tamarugal (Bermúdez, 1963). Esta situación nos permite conocer la intensa explotación a que se sometió a los bosques durante el período del auge salitrero.

Ricardo Latcham en sus Notas Preliminares de un Viaje Arqueológico a Quillagua describe que

en la Pampa del Tamarugal, a unos pocos kilómetros de Quillagua, se encuentran bosques de algarrobos de grandes extensiones, sepultados bajo las arenas del desierto. Estos son llamados minas de leña y son explotados por los vecinos del lugar para la lumbre de sus hogares y para hacer carbón de magnífica calidad, que se vende en las salitreras y en los puertos de Antofagasta, Tocopilla e Iquique, donde está muy apreciado por sus altas calorías (Latcham 1933:131).

Así, otra actividad importante de la época correspondió a la fabricación de carbón, la que se realizaba en el mismo terreno, preparando hornos adecuados, que consistían en cubrir los montones de leña con una capa de sacos y sobre ellos colocaban una capa de tierra humedecida (barro) dejando pequeños orificios que permitieran entrar el aire en 


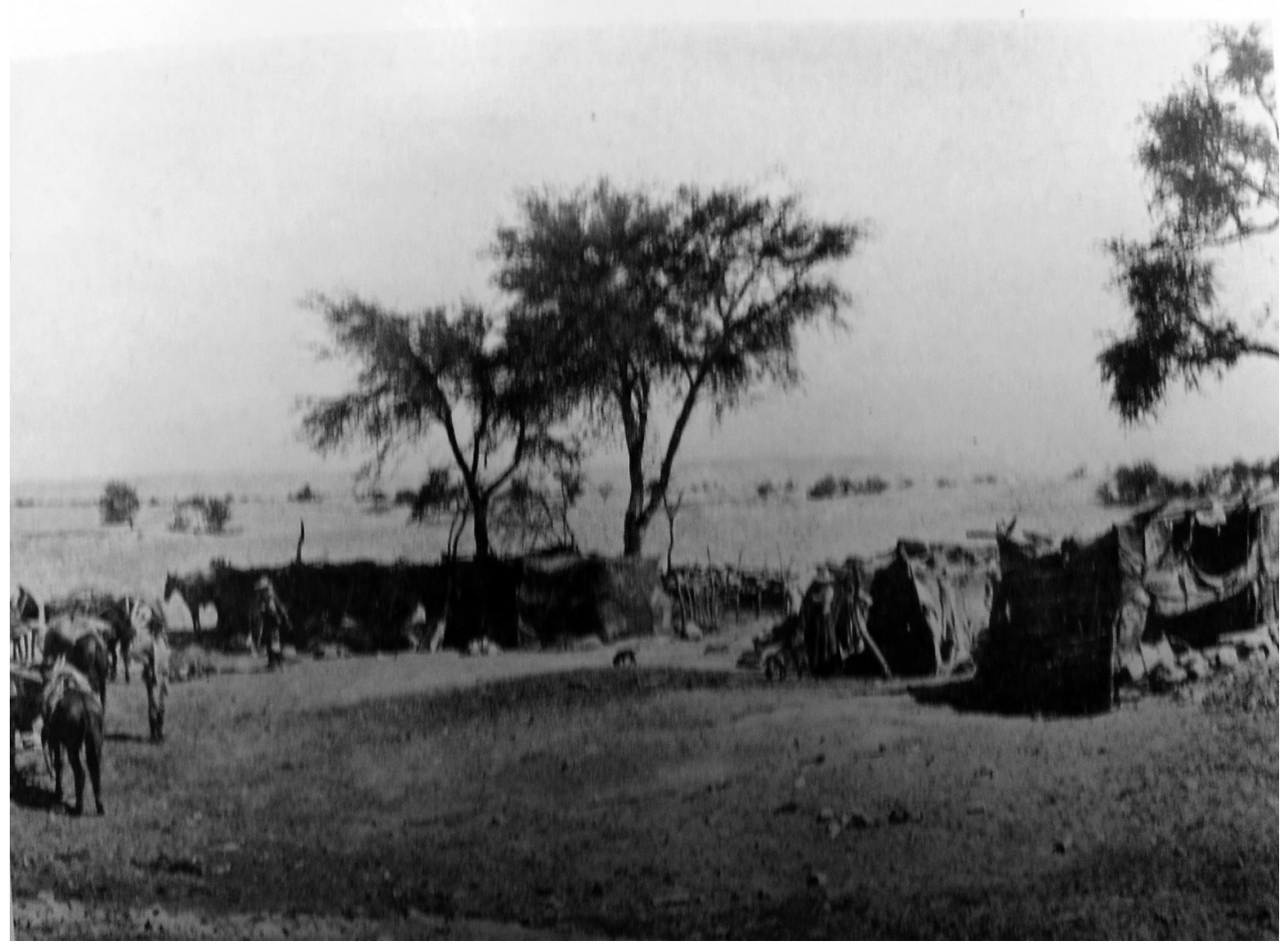

Figura 10. Vista de La Soledad, de acuerdo con Bowman (1924).

forma reducida, lo indispensable para la carbonización. Después de cuatro a seis días de iniciada la combustión, la leña se encontraba totalmente carbonizada, para ser vendida, preferentemente en los puertos de Arica, Iquique y Antofagasta (Figuras 11a y 11b).

La descripción de Isaiah Bowman también es reveladora. En su travesía desde Matilla a la Pampa del Tamarugal, señala:

our course for an hour or more was along this slope rather than across it ${ }^{2}$, and in this stretch we saw men digging fuel from the ground and loading it upon wagons from the station - an astonishing way in which to get firewood! All the more curious is it to hear the phrase "mining for wood". Even at the present day the leñador, or woodcutter, is a typical figure in the desert region, and his searches for the commodity of his trade, as those of the mine prospector, have contributed to the exploration of this inhospitable country (Bowman 1924:15) (Figura 12).

José María Casassas hace referencia también al concepto de las "minas de leña",

o sea, la utilización, en las faenas salitreras, de maderas secas, semifosilizadas en algunos casos, que se extraían del suelo pampino y se consideraban procedentes de antiguos arbustos, tamarugos principalmente, muertos al empeorar las condiciones climáticas, enterrados por las arenas arrastradas por los vientos o por los aluviones procedentes del altiplano (Casassas 1974:11-12).

\section{Resultados y conclusiones}

El Norte de Chile constituye un área invaluable desde el punto de vista arqueológico en donde la experiencia humana del pasado representa un caso único de manejo y apropiación de un medio árido 


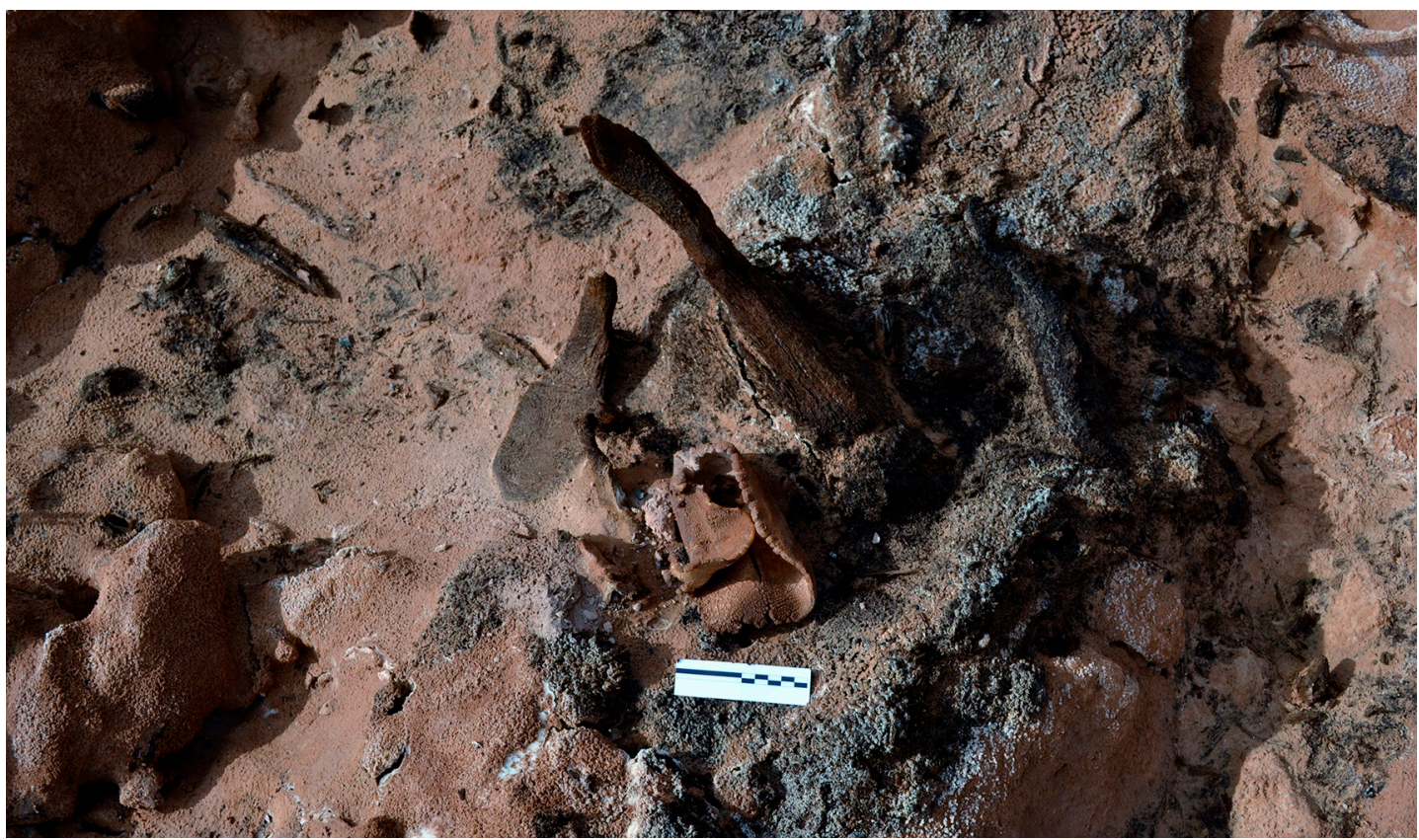

Figura 11a. Mina de carbón en bosque de tamarugos sector Llamara.

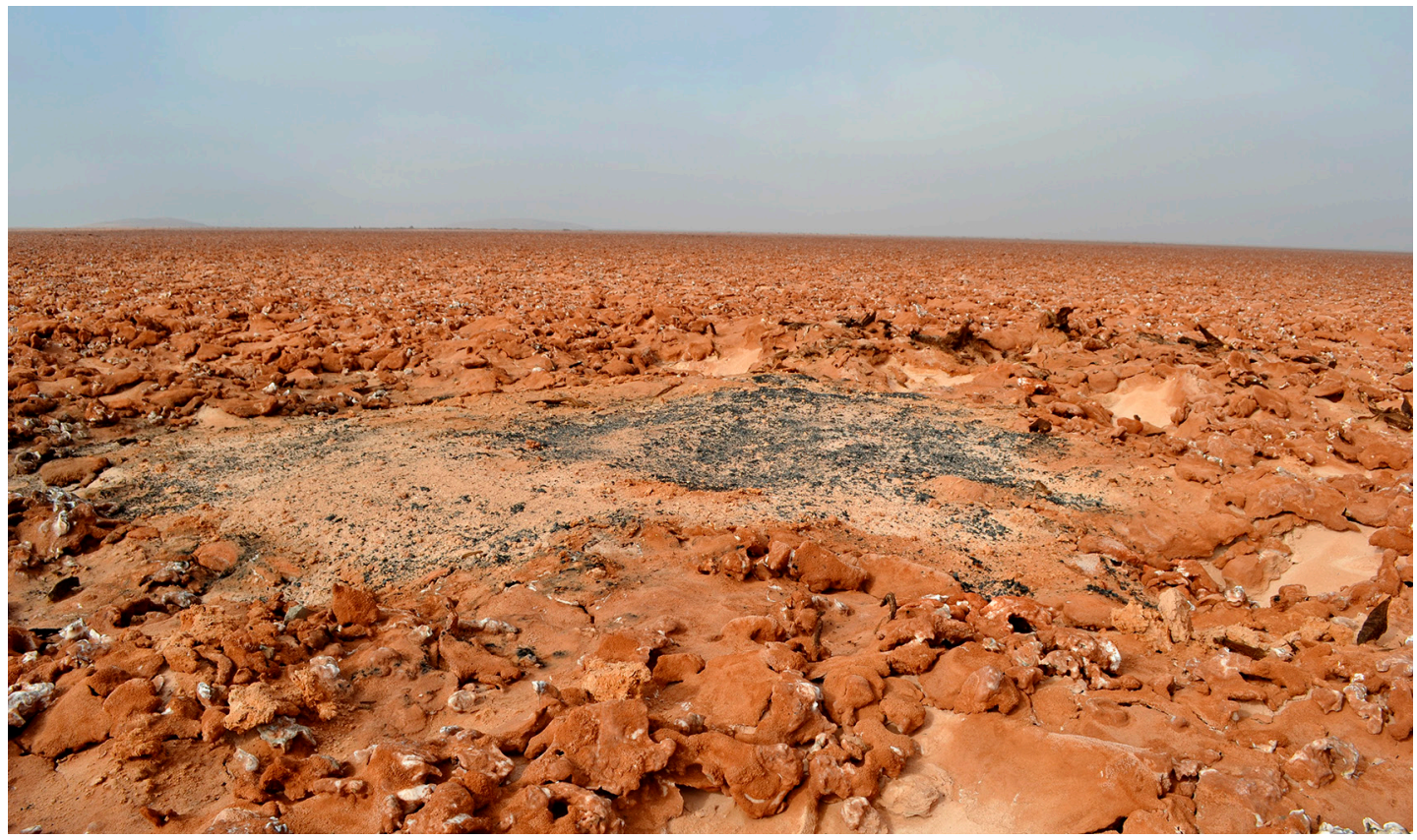

Figura 11b. Vista del bosque más antiguo de Llamara con evidencia de minas de carbón.

extremo como el desierto de Atacama. Sitios-aldeas como Ramaditas y Guatacondo, que constituyen los primeros signos de sedentarización en épocas formativas con antigüedad superior a los 2500 años, junto con manifestaciones de geoglifos y petroglifos en ambientes secos que permiten una excelente conservación, representan un potencial de desarrollo de suma importancia. Desde luego, es importante considerar que cada una de estas manifestaciones debe ser presentada en contexto 




Figura 12. Vista de Matilla de acuerdo con Bowman (1924).

con su ambiente y con otros sitios según revela la investigación arqueológica. Así, también es importante integrar en esta puesta en valor el rol de estos sitios, especialmente Ramaditas y Guatacondo en el registro histórico, durante la Colonia y su inclusión al pasado salitrero posterior en una suerte de continuidad histórica de causa-efecto.

El aporte etnohistórico es fundamental para conocer el comportamiento del medio ambiente desértico en los últimos siglos. Mediante el estudio de formaciones boscosas que pueden ser recuperadas por medio de la documentación histórica permitirá obtener las herramientas para conseguir secuencias climáticas ampliadas del paleoambiente en el desierto de Atacama. Esta investigación resulta fundamental en el propósito de lograr obtener una gama variada de muestras que contribuirán a completar la historia acerca de las condiciones pasadas del ambiente atacameño. De igual forma, también se obtiene conocimiento complementario de la especie Prosopis tamarugo sp.

Estos aspectos que se manifiestan en la recuperación, interpretación y reconocimiento del pasado, son importantes para la sustentabilidad de la identidad local. La existencia de bosques de tamarugos en tiempos tan tempranos -cerca de 10000 años- sugiere la disponibilidad cierta de recursos hídricos. Este factor abre la posibilidad que hayan transitado por este territorio grupos humanos en pos de animales pleistocénicos, circunstancia que constituye un potencial enorme para futuras investigaciones, tal vez, corroborando al propio Bollaert respecto del hallazgo de huesos de mastodontes en la Pampa del Tamarugal (Bollaert 1857:291-293).

\section{Agradecimientos}

El autor agradece el apoyo del arqueólogo Luis Pérez Reyes por su colaboración en la cartografía y relevamiento topográfico de los sitios Ramaditas y G-1. A Carlos María Chiappe y Carlos Zanolli y a Jorgelina Passo con la edición de este volumen. Agradezco, además, los comentarios de los evaluadores que tuvieron la oportunidad de revisar el manuscrito, sugerencias que han sido incorporadas. 
De la misma forma, agradezco la gestión de los editores generales de la Revista Diálogo Andino, Eugenio Sánchez y Alberto Díaz. Sin embargo, los juicios y conclusiones aportadas en la presente edición son de mi exclusiva responsabilidad.

Dedico este trabajo a la memoria de Ana María Lorandi con quien nos unió no solo compañerismo sino también una experiencia compartida en el intento por llevar a cabo investigaciones de disciplinas afines que se integran en una problemática de múltiples facetas. En este sentido, seguí muy de cerca la aproximación de la historia a la arqueología en lo que podría constituirse como la proyección del pasado precolombino a los tiempos posteriores donde juega un rol fundamental la experiencia de las diferentes sociedades americanas y en especial aquellas andinas, dejando un rastro indisoluble que es necesario estudiar cada vez con más fuerza. De allí que el ejemplo que nos delineó Ana María por medio de sus investigaciones, complementando y reforzando los hechos del pasado precolombino con las fuentes etnohistóricas, cobre plena vigencia, constituyendo un legado para las nuevas generaciones (Figura 13).

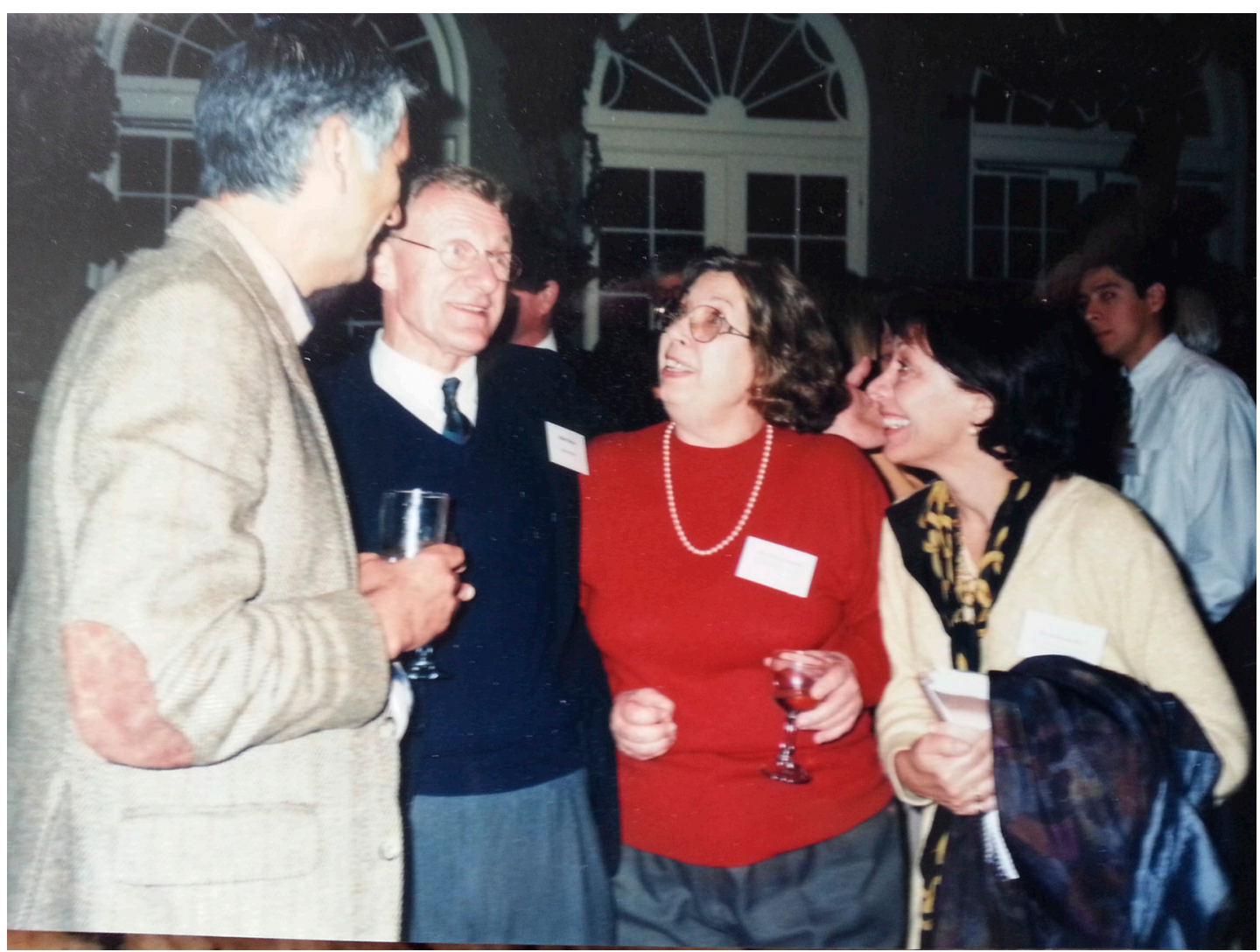

Figura 13. Ana María Lorandi y camaradas arqueólogos asistiendo a la Conferencia de Dumbarton Oaks, Harvard University en Washington D.C., 1993. 


\section{Referencias Citadas}

Advis, $\mathrm{P}$.

2008 El Desierto Conmovido, Paso de las Hueste de Almagro por el Norte de Chile. Ediciones Universidad Arturo Prat, Iquique.

Balsana, A.

1594 Relaciones Geográficas de Indios. Biblioteca de Autores Españoles, Volumen 2, Paraguay.

Bermúdez, $\mathrm{O}$.

1963 Historia del Salitre. Universidad de Chile, Santiago.

Bertrand, A.

1879 Carta Geográfica de los desiertos de Tarapacá y de Atacama Noticias del departamento Litoral de Tarapacá y sus Recursos. Oficina Hidrográfica de Chile, Informe $\mathrm{N}^{\mathrm{o}} 1$ y $N^{\circ}$ 2. Imprenta Nacional, Santiago.

Bertrand, A.

1879 Departamento de Tarapacá, Aspecto Jeneral del Terreno, su Clima i sus Producciones. Imprenta de la República, Santiago.

Bibar, J. de.

1966 [1558] Crónica y Relación Copiosa de los Reynos de Chile hecha por Jerónimo de Bibar, natural de Burgos, 1558. (Transcripción de Irving A. Leonard), Edición del Fondo Histórico y Bibliográfico José Toribio Medina.

Billinghurst, G. E.

1886 Estudio sobre la geografía de Tarapacá. Imprenta de El Progreso, Santiago.

Bittmann, B.

1988 Recursos y Supervivencia en el Desierto de Atacama Recursos Naturales Andinos, editado por S. Masuda. Universidad de Tokio, Tokio.

Boletín Cámara Diputados

2014 9903-12, Periodo Legislativo 2014-2018, Legislatura 362, Sesión No 124, Fecha 04-3-2015.

Boletín de la Guerra del Pacífico

1879-1881 Departamento de Tarapacá, Aspecto Jeneral del Terreno, su Clima y sus Producciones $\mathrm{N}^{\circ} 33$.

Bollaert, W.

1851 Observations on the Geography of Southern Peru, Including Survey of the Province of Tarapaca and Route to Chile by the Coast of the Desert of Atacama. Journal of the Royal Geographical Society of London 21:99-130, Londres.

Bollaert, W.

1857 On the occurrence of bones of mastodon in Chile. Quarterly Journal of the Geological Society 13 (1-2):291-293.

Bowman, I.

1924 Desert Trails of Atacama, American Geographical Society. Publicacion No. 5, New York.

Casassas, J.

1974 La Región Atacameña en el siglo XVII. Universidad del Norte, Antofagasta.

Castro, C. L., P. Guerrero Oñate y C. Figueroa Cerna.

2017 La expedición de Antonio Raimondi a la provincia de Tarapacá y la construcción estatal de un territorio nacional peruano: comentarios y transcripción de su cuaderno de campo (1853-1854). Estudios Atacameños 54:111-152.

Clarke, J.

2006 Antiquity of aridity in the Chilean Atacama Desert. Geomorphology 73:101-114.
CONAF, Corporación Nacional Forestal.

2015 Corporación Nacional Forestal Región I Cuenta Pública, Iquique.

Couyoumdjiam, R. y H. Larraín.

1975 El plano de Quebrada de Tarapacá, de don Antonio O’Brien. Su valor geográfico y socio-antropológico. Norte Grande 1 (3-4):329-362.

Cummings, L., C. Nepstad-Thornberry y K. Puseman.

2005 Restos Paleofecales del sitio de Ramaditas, Norte de Chile: Aspectos sobre dieta y salud en el Formativo Medio y Tardío. En Arqueología del Desierto de Atacama, La Etapa Formativa en el Area de Ramaditas/Guatacondo. Editado por M.A.Rivera, pp. 195-210. Editorial UB/Lom, Santiago.

Dodd, J. y M. Rivera.

2012 Variations in groundwater availability during the past 9,000 years in the Atacama Desert, Chile: A subannual record of oxygen isotope values from Prosopis tamarugo tree rings. American Geophysical Union Meeting H53A1509, San Francisco.

Dean, J. y D. Doyel.

2006 Culture, Environment, and Adaptation: Perspectives from the Ancient Southwest. Environmental Change and Human Adaptation in the Ancient American Southwest, editado por Dean and Doyel, pp. 1-9. University of Utah Press, Utah.

Espinoza, E.

1897 Geografía Descriptiva de la República de Chile, Cuarta edición. Imprenta Barcelona, Santiago.

Garcilaso de la Vega.

Inca 1962 (1963/1609) Comentarios Reales de los Incas, I ${ }^{\mathrm{a}} \mathrm{y}$ II ${ }^{\mathrm{a}}$ Parte Biblioteca de Autores Españoles, tomos CXXXIII y CXXXXIV, Obras Completas de Garcilaso de la Vega, II y III. Ediciones Atlas, Madrid.

Grosjean, M., L. Núñez, I. Cartagena y B. Messerli. 1997 Mid-Holocene climate and culture change in the Atacama Desert, Northern Chile. Quaternary Research 48:239-246.

Hidalgo, J.

1985 Proyectos coloniales inéditos de riego del desierto: Azapa (Cabildo de Arica, 1619); Pampa Iluga (O'Brien, 1765) y Tarapacá (Mendizábal, 1807). Chungará 14:183-222.

Hyslop, J. y M. Rivera.

1984 The Inka Road in the Atacama Desert. Archaeology 37(6):33-39.

Larraín, H.

1974 Antecedentes históricos para un estudio de la reutilización de suelos agrícolas en la Pampa del Tamarugal, Provincia de Tarapacá, Chile. Norte Grande 1(1):9-22.

Latcham, R.

1933 Notas Preliminares de un Viaje Arqueológico a Quillagua. Revista Chilena de Historia Natural, pp. 130-138.

Latorre, C., J.L. Betancourt y M. Arroyo.

2006 Late Quaternary vegetation and climate history of a perennial river canyon in the rio Salado basin $\left(22^{\circ} \mathrm{S}\right)$ of Northern Chile. Quaternary Research 65:450-466.

Lozano Machuca, J.

1965 (1581) Carta del Factor de Potosí al Virrey del Perú, en donde se describe la Provincia de los Lipes. Relaciones Geográficas de Indias, Perú, II, editado por Marcos Jiménez 
de la Espada, Apéndice III, xxi-xxviii. Biblioteca de Autores Españoles, Madrid.

Malaspina, A.

2001 [1799] The Malaspina expedition 1789-1794. Journal of the voyage by Alejandro Malaspina, editado por Andrew David. Hakluyt Society y Museo Naval de Madrid, Londres. Meighan, C.

1980 Archaeology of Guatacondo. Prehistoric Trails of Atacama, editado por C. Meighan y D.L True, Monumental Archaeologica 7, Institute of Archaeology, pp. 99-126, University of California, Los Angeles.

Mendizábal, F.

1808 Informe sobre la imposibilidad de dar agua al mineral de Guantajaya, remitido al virrey del Perú, con carta No 256 de septiembre de 1808, Lima 625. Archivo General de Indias, Sevilla.

Molina, C. de.

1934 Conquista y población del Perú. Boletín Academia de la Historia Chile, Imprenta Universitaria, Santiago.

Mostny, G.

1970 La Subárea arqueológica de Guatacondo. Boletín Museo Nacional de Historia Natural, 29:271-287.

Mostny, G.

1980 The Archaeological Zone of Guatacondo Prehistoric Trails of Atacama C. editado por Meighan y D.L True. Monumental Archaeologica 7, Institute of Archaeology, pp. 91-97, University of California, Los Angeles.

Niemeyer, H. y M. Rivera.

1983 El Camino del Inca en el Despoblado de Atacama. Boletín del Departamento de Ciencias Antropológicas, Universidad de Chile, 9:91-193.

O'Brien, A.

1765 Plano que manifiesta el valle o Pampa de Yluga en el Thenientazgo de Tarapacá del Corregimiento de la Ciudad de San Marcos de Arica con las quebradas mas notables que desembocan en él; el Agua que por dichas Quebradas baja en tiempo de lluvias en la Cordillera; los Bosques y Tierras que sembraban en tiempos pasados cuando llovía en dicho Valle; los Caminos que lo cruzan y los sitios que tienen nombre en dicho Valle", firmado el 14 de Agosto de 1765 en el pueblo de Tarapacá; conservado en el Museo Naval de Madrid, Bandeja LI, Carpeta A-3.

Olson, E., J. Dodd y M. Rivera.

2014 Mid-Holocene Water Availability in the Atacama Desert, Chile recorded in tree ring oxygen isotope variability at the Ramaditas archaeological site: Evidence for climate change and anthropogenic landscape alteration. Past Global Changes (PAGES) Conference, Medellin, Colombia.

Paz Soldán, M.F.

1878 Verdaderos Límites entre el Perú y Bolivia, Lima.

Pinto, R.

2009 Biodiversidad del Salar de Llamara. Informe Final Proyecto Fondo de Protección Ambiental 01-009-2008.

Raimondi, A.

1853 Provincia de Tarapacá, Libreta $N^{\circ} 2$. Colección Antonio Raimondi Archivo General de la Nación del Perú.
Rech, J.A., J. Quade y J.L. Betancourt.

2002 Late Quaternary paleohydrology of the central Atacama Desert, Chile $\left(22-24^{\circ} \mathrm{S}\right)$. Geological Society of America Bulletin 114:334-348.

Rech, J.A., J.S. Pigati, J. Quade y J.L. Betancourt.

2003a Re-evaluation of mid-Holocene deposits at Quebrada Puripica, northern Chile, Palaeogeography, Palaeoclimatology, Palaeoecology 194(1-3):207-222.

Rech, J.A., J. Quade y W.S. Hart.

2003b Isotopic evidence for the source of $\mathrm{Ca}$ and $\mathrm{S}$ in soil gypsum, anhydrite and calcite in the Atacama desert, Chile Geochimica et Cosmochimica 67(4):575-586.

Rivera, M.

1987 Tres Fechados Radiométricos de Pampa Alto Ramírez, N. de Chile, Chungara 18:7-13.

Rivera, $\mathrm{M}$.

2002 Historias del Desierto, Arqueología del Norte de Chile. Editorial del Norte, La Serena.

Rivera, $\mathrm{M}$.

2005 Arqueología del Desierto de Atacama, La Etapa Formativa en el Área de Ramaditas/Guatacondo, Editorial UB/Lom, Santiago.

Rivera, M., J. Moya, D. Shea.

2010 Dendrocronología en la Pampa del Tamarugal, Desierto de Atacama, Norte de Chile, Dialogo Andino 36:33-50.

Rivera, M. y J. Dodd.

2013 Domesticando el desierto. Medio ambiente y ocupaciones humanas en Ramaditas, Desierto de Atacama, Dialogo Andino 41: 45-60.

Scarborough, V.

2003 The Flow of Power. Ancient Water Systems and Landscapes. The School of American Research, Santa Fe.

Smith, G. y W. Bollaert.

1860 Plano: The Province of Tarapaca on the Department of Arequipa. En Antiquarian, ethnological and other researches in New Granada, Equador, Peru and Chile Bollaert, Trubner $\&$ Co. London.

Solezzi, M.

1993 Pampa del Tamarugal, La Destrucción del Monte de la Soledad (Ciclo Salitrero). Camanchaca 14:6-8.

Tartaglia, L.G.

1980 An Analysis of the Cultivated Plants Remains from Guatacondo, Chile Prehistoric Trails of Atacama, editado por C. Meighan y D. True. Institute of Archaeology, pp.127133, University of California, Los Angeles.

Trelles A., E.

1982 Lucas Martínez Vegazo: Funcionamiento de una encomienda peruana inicial. PUC Fondo Editorial, Lima.

True, D. y H. Crew.

1980 Archaeological Investigations in Northern Chile: Tarapaca 2A Prehistoric Trails of Atacama, editado por C. Meighan y D.L True. Monumental Archaeologica 7, Institute of Archaeology, pp. 59-89, University of California, Los Angeles.

Zapater, $\mathrm{H}$.

1973 Los Aborígenes Chilenos a Través de Cronistas y Viajeros. Editorial Andrés Bello, Santiago.

\section{Notas}

1 Especialmente el gran tamarugal en torno al Salar de Pintados, Oficina salitrera Diana y Cumiñalla, Pazos hasta Pozo Almonte y la Quebrada de Tambillos (Larraín 1974:18).
2 Se refiere a la bajada desde Matilla hacia el SO. 
